\title{
Combustion Characteristics of $\mathbf{C}_{5}$ Alcohols and a
}

\section{Skeletal Mechanism for HCCI Combustion}

\section{Simulation}

\author{
Sungwoo Park ${ }^{1 *}$, Suk Ho Chung ${ }^{1}$, Tianfeng Lü ${ }^{2}$, S. Mani Sarathy ${ }^{1}$
}

${ }^{1}$ Clean Combustion Research Center, King Abdullah University of Science and Technology, Thuwal 23955-6900, Kingdom of Saudi Arabia

${ }^{2}$ Department of Mechanical Engineering, University of Connecticut, Storrs, Connecticut 062693139, United States

\section{KEYWORDS}

2-methylbutanol, iso-pentanol, ignition delay, intermediate temperature heat release, skeletal mechanism, HCCI engine combustion 


\section{ABSTRACT}

$\mathrm{C}_{5}$ alcohols are considered alternative fuels because they emit less greenhouse gases and fewer harmful pollutants. In this study, the combustion characteristics of 2-methylbutanol (2-methyl-1butanol) and iso-pentanol (3-methyl-1-butanol) and their mixtures with primary reference fuels (PRFs) were studied using a detailed chemical kinetic model obtained from merging previously published mechanisms. Ignition delay times of the $\mathrm{C}_{5}$ alcohol/air mixtures were compared with PRFs at 20 and 40 atm. Reaction path analyses were conducted at intermediate and high temperatures to identify the most influential reactions controlling ignition of $\mathrm{C}_{5}$ alcohols. The direct relation graph with expert knowledge methodology was used to eliminate unimportant species and reactions in the detailed mechanism, and the resulting skeletal mechanism was tested at various homogeneous charge compression ignition (HCCI) engine combustion conditions. These simulations were used to investigate the heat release characteristics of the methylsubstituted $\mathrm{C}_{5}$ alcohols, and the results show relatively strong reactions at intermediate temperatures prior to hot ignition. $\mathrm{C}_{5}$ alcohol blending in PRF75 in HCCI combustion leads to a significant decrease of low temperature heat release (LTHR) and a delay the main combustion. The heat release features demonstrated by $\mathrm{C}_{5}$ alcohols can be used to improve the design and operation of advanced engine technologies. 


\section{Introduction}

Stringent emission regulations and health concerns related to the combustion of traditional fuels has elevated interest in alternative fuels and fuel additives. Oxygenated fuels have been considered alternative fuels or as fuel additives to fossil fuels because they emit less $\mathrm{NO}_{\mathrm{x}}$ and particulates. ${ }^{1}$ In addition, the production of oxygenated fuels from renewable sources can neutralize $\mathrm{CO}_{2}$ emissions from combustion devices; however, before they are applied, their fundamental combustion characteristics need to be evaluated. ${ }^{2}$ For example, although ethanol is a first-generation biofuel that has attractive characteristics as an alternative bio-based alcohol fuel extender for petroleum fuels, it also imparts disadvantages such as a high O/C ratio, high hygroscopicity, and low energy density, which can cause problems with fuel storage and blending in combustion engines. In contrast, higher alcohols have lower hygroscopicity and corrosivity, higher energy density, and can be readily blended with hydrocarbon fuels. Therefore, higher alcohol fuels, such as $\mathrm{C}_{4}$ and $\mathrm{C}_{5}$ alcohols, have been studied as next-generation biofuels, and extensive combustion chemistry studies on butanol isomers have been conducted over the last several years. ${ }^{3-18}$

The physical and chemical properties ${ }^{1}$ of several alcohol fuels are presented in Table 1. The research octane number (RON) of 2-methylbutanol is unknown but could be estimated using the correlation between RON and shock tube (ST) ignition delay time under specific conditions (e.g., $835 \mathrm{~K}$ and $20 \mathrm{~atm}) .{ }^{19}$ In general, the octane ratings of $\mathrm{C}_{5}$ and larger alcohols are lower than those of $\mathrm{C}_{1}-\mathrm{C}_{3}$ alcohols; this higher propensity for ignition (increased cetane number) makes larger alcohols suitable for compression-ignition (CI) engine applications. ${ }^{1}$ 
Table 1. Physical and chemical properties of alcohol and gasoline. ${ }^{1}$

\begin{tabular}{lccccc}
\hline & ethanol & iso-butanol & iso-pentanol & 2-methylbutanol & Gasoline \\
\hline Molecular weight & 46.06 & 74.11 & 88.14 & 88.14 & 111.19 \\
Oxygen content (wt\%) & 0.35 & 0.22 & 0.18 & 0.18 & 0 \\
Lower heating value (MJ/L) & 21.4 & 26.6 & 27.8 & 28.2 & $30-33$ \\
Boiling Point $\left({ }^{\circ} \mathrm{C}\right)$ & 78 & 108 & 130 & 129 & $27-225$ \\
RON & 109 & 105 & 94 & - & $88-98$ \\
MON & 90 & 90 & 84 & - & $80-88$ \\
Solubility in water at $25^{\circ} \mathrm{C}($ wt $\%)$ & Miscible & 8.1 & 2.7 & & Negligible \\
\hline${ }^{a}$ values for 2-methylbutanol from Li et al. ${ }^{20}$ & & &
\end{tabular}

Attention to alcohol combustion research on a $\mathrm{C}_{5}$ family of alcohols, including $n$ pentanol $^{21-25}$, iso-pentanol (3-methyl-1-butanol, $\overbrace{\mathrm{OH}})^{26-30}$, and 2-methylbutanol (2methyl-1-butanol, $\left.{ }^{\mathrm{OH}}\right)^{31-34}$ has increased in recent years because longer-chain alcohols are better suited for combustion engines. However, there have been limited studies on $\mathrm{C}_{5}$ alcohol combustion. Tang et al. ${ }^{24}$ measured the high-temperature ignition delay times of $\mathrm{C}_{5}$ alcohols $(n$ pentanol, iso-pentanol, and 2-methylbutanol) in shock tubes with varying equivalence ratios at temperatures above $1100 \mathrm{~K}$ and pressures of 1 and $2.6 \mathrm{~atm}$. Their experimental results showed that the ignition delay times and global activation energy decreased in the order of iso-pentanol to 2-methylbutanol to $n$-pentanol. The CNRS Orleans group measured the concentrations of reactants, intermediate species, and products of $i s o$-pentanol ${ }^{26}$ and 2 -methylbutanol ${ }^{31}$ in a jetstirred reactor at 10 atm and simulated their experiments using detailed chemical kinetic mechanisms. In 2012, Zhao et al. ${ }^{22}$ calculated pressure- and temperature-dependent rate constants for the thermal decomposition of pentanol isomers. In the same year, Welz and coworkers $^{28}$ studied the low-temperature oxidation pathways of iso-pentanol using photoionization mass spectrometry to emphasize the importance of the formation of iso-pentanal (3methylbutanal) and enol species. More recently, Lucassen and co-workers investigated the 
combustion chemistry of 2-methylbutanol ${ }^{33}$ and iso-pentanol ${ }^{30}$ in low-pressure premixed flames using flame-sampling molecular-beam mass spectrometry along with detailed chemical kinetic models. In 2013, $\mathrm{Li}$ and co-workers ${ }^{20,25}$ measured laminar-burning velocities of $\mathrm{C}_{5}$ alcohol isomers at elevated temperatures and pressures using a spherically propagating flame. And earlier this year, Zhang et al. ${ }^{32}$ measured pyrolysis species of 2-methylbutanol in a flow reactor using synchrotron vacuum ultraviolet photoionization mass spectrometry at low and atmospheric pressures. Their results showed that the decomposition of 2-methylbutanol is similar to that of iso-butanol rather than that of $n$-butanol. Previously, Tsujimura et al. ${ }^{27}$ proposed a chemical kinetic model for iso-pentanol, including comprehensive reaction pathways at low, intermediate, and high temperatures, and validated it against ignition delay times. Meanwhile, Sarathy and coworkers $^{29}$ provided a wide range of experimental data for the oxidation of iso-pentanol and proposed a detailed chemical kinetic model. Most recently, Park et al. ${ }^{34}$ proposed a chemical kinetic model for 2-methylbutanol and compared it against existing and new experimental data on its combustion.

Longer-chain alcohols could significantly increase the biofuel content in blended fuels due to their higher energy content, better engine compatibility, and lower water solubility. Campos-Fernández et al. ${ }^{35}$ studied the short-term performance of a direct-injection diesel engine fueled with different $n$-pentanol/diesel fuel blends and found a slight engine power loss and an increase in brake thermal efficiency when the engine was fueled with higher alcohol blends. In 2000, Gautam and $\operatorname{Martin}^{36}$ investigated the combustion characteristics of alcohol/gasoline blends in a single-cylinder engine and their results showed that higher-alcohol/gasoline blends have a greater resistance to knock than neat gasoline. Ten years later, Yang and co-workers ${ }^{37}$ studied the fundamental characteristics of iso-pentanol as a fuel for homogeneous charge 
compression ignition (HCCI) engines. They found that iso-pentanol displays intermediate temperature heat release (ITHR) characteristics, which is important for optimal engine operation. HCCI engines combine the advantages of a spark ignition (SI) engine with a CI engine, but they struggled to control the ignition delay time and the rate of combustion.

The purpose of this study is to investigate the ignition and heat release characteristics of methyl-substituted pentanol isomers, 2-methylbutanol and iso-pentanol, to improve our understanding of their combustion with analyses using a detailed chemical kinetic model. We also present a new skeletal mechanism suitable for HCCI combustion simulations and test the model against various $\mathrm{HCCI}$ engine conditions to help explain the combustion properties of $\mathrm{C}_{5}$ alcohols in an HCCI engine for a wide range of conditions including intake pressure, intake temperature, and engine speed.

\section{Chemical kinetic model}

All simulations were conducted in CHEMKIN PRO $15112^{38}$ using the appropriate reactor modules. The detailed chemical kinetic model used in this study results from the merging of previously published mechanisms. The AramcoMech $1.3^{39}$ for the oxidation of small hydrocarbon was utilized as the base mechanism, which has been widely validated for $C_{1}-C_{2}$ species for improved prediction of ignition delay times, flame speeds, and flame speciation. The 2-methylbutanol ${ }^{34}$ and iso-pentanol ${ }^{29}$ sub-schemes were included for low- and high-temperature chemistry of $\mathrm{C}_{5}$ alcohols, which have been previously validated against various experimental data sets such as ignition delay times, laminar burning velocity, and species mole fraction in jetstirred reactor (JSR). The LLNL (Lawrence Livermore National Laboratory) Gasoline Surrogate sub-scheme ${ }^{40}$ was also added to allow computations of $\mathrm{C}_{5}$ alcohols mixed with primary reference 
fuels (PRFs). The resulting detailed mechanism used in this study involved 1482 species and 6573 reaction steps. The detailed and skeletal mechanisms and thermodynamic properties are available as supplementary material.

\section{Results and discussion}

Autoignition delay times

Ignition delay times for a) stoichiometric and b) fuel-lean $(\phi=0.5)$ 2-methylbutanol and iso-pentanol in air were simulated using the adiabatic constant volume homogenous reactor model in CHEMKIN PRO $^{38}$, and the results were compared with experimental data ${ }^{27,34}$ at 20 atm, as shown in Figure 1. The model was also tested against ignition delay times measured in the rapid compression machine $(\mathrm{RCM})$ by running homogeneous variable volume history simulations accounting for the compression stroke and post-compression expansion/heat loss in the experiments. In this study, the onset of ignition for constant volume simulation is the time corresponding to the maximum rate of temperature rise ( $\max \mathrm{dT} / \mathrm{dt}$ ), which corresponds to the maximum pressure rise rate $(\max \mathrm{dP} / \mathrm{dt}$ ). The ignition delay time in the $\mathrm{RCM}$ is defined as the difference in time between the end of compression and the maximum of the time derivative of the pressure. The ignition data for iso-pentanol/air mixtures were measured using a ST at NUI (National University of Ireland) Galway and an RCM at the University of Connecticut ${ }^{27}$, and the data for 2-methylbutanol/air mixtures were obtained using a high-pressure shock tube (HPST) at $\mathrm{KAUST}^{34}$. Overall, the proposed model for $\mathrm{C}_{5}$ alcohols well predicts the ST and RCM experimental data within a factor of 2 . Figure 1 also presents the ignition data for PRF84 ${ }^{41}$ (a mixture of $84 \%$ iso-octane and $16 \% n$-heptane in volume fraction). Experimental and computational results indicate that the ignition delay times of 2-methylbutanol/air mixtures are 
similar to those of iso-pentanol/air mixtures at intermediate temperatures $(950-1050 \mathrm{~K})$, but, at higher temperatures $(\mathrm{T}>1050 \mathrm{~K})$, ignition delay times and overall activation energy of 2methylbutanol are lower than those for iso-pentanol. In contrast, the simulated ignition times of 2-methylbutanol are longer than those of iso-pentanol at the lowest temperatures. The ignition behavior of both fuels in the high-temperature region is consistent with shock tube ignition data acquired at 1 and 2.6 atm by Tang et al. ${ }^{24}$ Figure 1 also shows that the ignition times of $\mathrm{C}_{5}$ alcohols are slightly faster than for PRF84 in the intermediate-temperature region (950-1050 K). However, pronounced negative temperature coefficient (NTC) behavior is observed for PRF84, and the ignition delay times of $i$ so-pentanol become slower than PRF84 near the NTC transition region, where low-temperature reactivity of PRF84 increases. The simulated ignition times of $\mathrm{C}_{5}$ alcohols also show decreased reactivity under low-temperature conditions. 

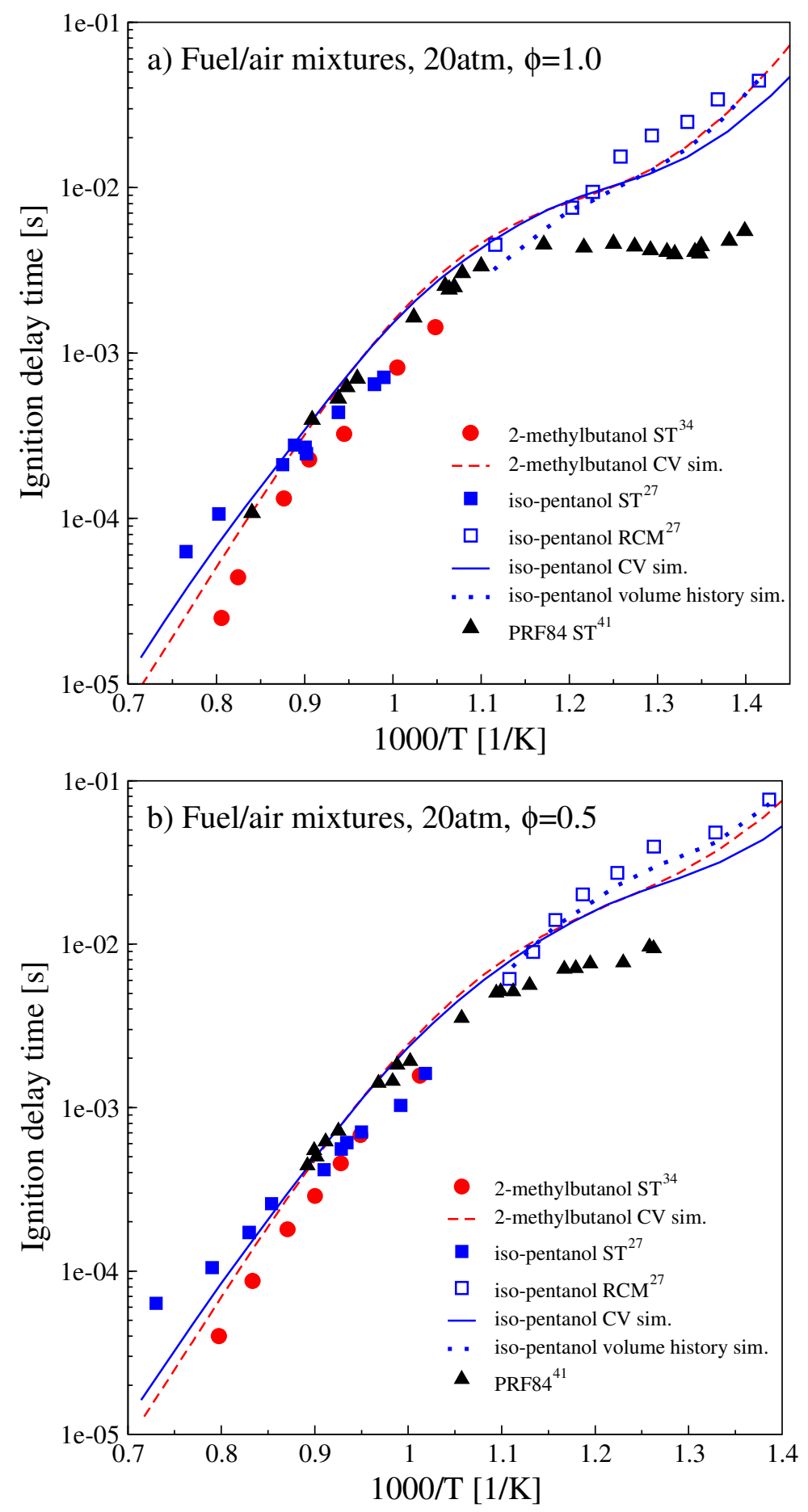

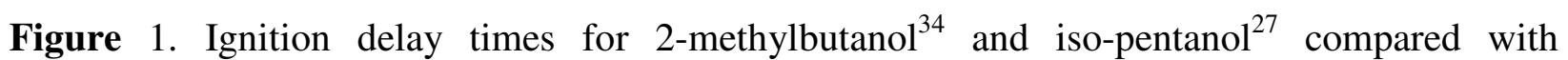
simulations at $20 \mathrm{~atm}$. Experimental data for PRF84 ${ }^{41}$ are also presented. 
Ignition delay times for 2-methylbutanol and iso-pentanol in air were also compared at 40 atm using the HPST at KAUST ${ }^{34}$, and ignition data for iso-pentanol/air mixtures were measured in a ST at the Rensselaer Polytechnic Institute ${ }^{29}$. Figure 2 displays the experimental data at 40 atm for stoichiometric fuel/air mixtures with $n$-heptane ${ }^{42}, \mathrm{PRF}_{4} 4^{41}$, and iso-octane ${ }^{42}$. We observed a similar trend at $40 \mathrm{~atm}$ as was observed at $20 \mathrm{~atm}$. In the intermediate temperature region $(800-1000 \mathrm{~K})$, the ignition data of 2-methylbutanol/air mixtures are very close to isopentanol/air ignition data, but at high temperatures, ignition delay times of 2-methylbutanol are shorter than for iso-pentanol. (i.e., ignition delay times and overall activation energy of 2methylbutanol are lower than iso-pentanol). Between intermediate- and high-temperatures, the ignition delay times of $\mathrm{C}_{5}$ alcohols are also slightly faster than for iso-octane and PRF84. However, ignition delay times for both $\mathrm{C}_{5}$ alcohols becomes slower than for $n$-heptane, PRF84, or iso-octane at the lowest temperatures due to a lack of low-temperature reactivity of $\mathrm{C}_{5}$ alcohols.

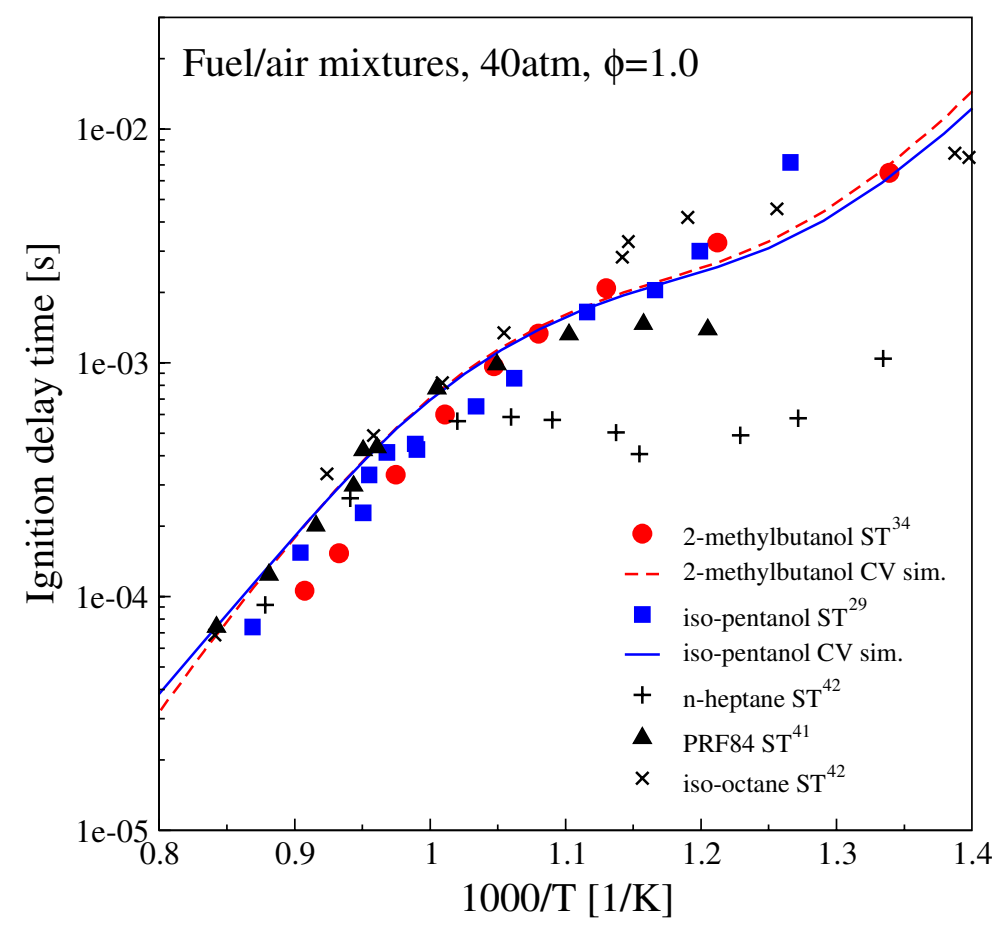


Figure 2. Ignition delay times for 2-methylbutanol ${ }^{34}$ and iso-pentanol ${ }^{29}$ compared with $^{2}$ simulations at $40 \mathrm{~atm}$. Experimental data for $\mathrm{n}$-heptane ${ }^{42}, \mathrm{PRF}^{41}{ }^{41}$, and iso-octane ${ }^{42}$ are also presented.

To highlight the most influential reactions controlling the ignition of both $\mathrm{C}_{5}$ alcohol/air mixtures, reaction path analyses for stoichiometric and fuel lean $(\phi=0.5)$ mixtures were conducted at 950 and $1350 \mathrm{~K}$ under 20 atm using the detailed chemical kinetic model. Figure 3 displays the dominant reaction pathways for the consumption of a) 2-methylbutanol and b) isopentanol; italicized and bold texts refer to intermediate- (950K) and high-temperature (1350K) conditions, respectively. The reaction paths were obtained from the rate of production analysis in CHEMKIN $\mathrm{PRO}^{38}$ at a time corresponding to $20 \%$ of the fuel consumed. Fuels are mainly consumed by $\mathrm{H}$-atom abstraction reactions in favor of the $\alpha$-site at $950 \mathrm{~K}$ because of its low $\mathrm{C}$-H bond dissociation energy. Approximately $50 \%$ of fuels are consumed by the $\mathrm{H}$-atom abstraction at the $\alpha$-site to produce $\alpha$-hydroxypentyl radicals, which mainly react with molecular oxygen to produce $\mathrm{C}_{5}$ aldehyde species and $\mathrm{HO}_{2}$ (2-methylbutanal from 2-methylbutanol and iso-pentanal from iso-pentanol). These reactions are low-temperature chain terminating pathways that inhibit low-temperature ignition of alcohols. ${ }^{43}$ The other fuel radicals are confronted with competition between $\beta$-scission decomposition reactions and $\mathrm{O}_{2}$ addition reactions to radical sites to form hydroxypentyl peroxy (ROO) radicals (gray pathways in Figure 3). These ROO radicals mainly undergo isomerization to form hydroxypentyl hydroperoxide (QOOH), the conventional lowtemperature chain-branching reaction. Therefore, fuel ignition is largely dependent on the formation of 2-methylbutanal and iso-pentanal as well as low-temperature chemistry at $950 \mathrm{~K}$. $\mathrm{H}$-atom abstraction reactions are still the dominant fuel consumption pathways at $1350 \mathrm{~K}$ favoring the a-site. In addition, the unimolecular fuel decomposition reactions become important under high-temperature conditions. Approximately $16 \%$ of 2-methylbutanol is decomposed to 
form 2-butyl and hydroxymethyl radicals, and the formation of methyl and $\mathrm{\gamma}$-hydroxybutyl radicals accounts for $6 \%$ of iso-pentanol consumption. Subsequently, $\beta$-scission reactions of fuel radicals lead to the formation of smaller radicals and unsaturated species (e.g., alkenes, enols, and/or aldehydes) in favor of $\mathrm{C}-\mathrm{C}$ or $\mathrm{C}-\mathrm{O}$ bond cleavage. Ethylene $\left(\mathrm{C}_{2} \mathrm{H}_{4}\right)$ and butene isomers $\left(\mathrm{C}_{4} \mathrm{H}_{8}\right.$, 1-butene, 2-butene) are major intermediate species of 2-methylbutanol, while propene $\left(\mathrm{C}_{3} \mathrm{H}_{6}\right)$ and iso-butene $\left(i \mathrm{C}_{4} \mathrm{H}_{8}\right)$ are major intermediate species of $i s o$-pentanol. Fuel consumption pathways are insensitive to equivalence ratio, but $\mathrm{O}_{2}$ addition reactions become more important at $950 \mathrm{~K}$ for lean mixtures due to the higher $\mathrm{O}_{2}$ mole fraction.

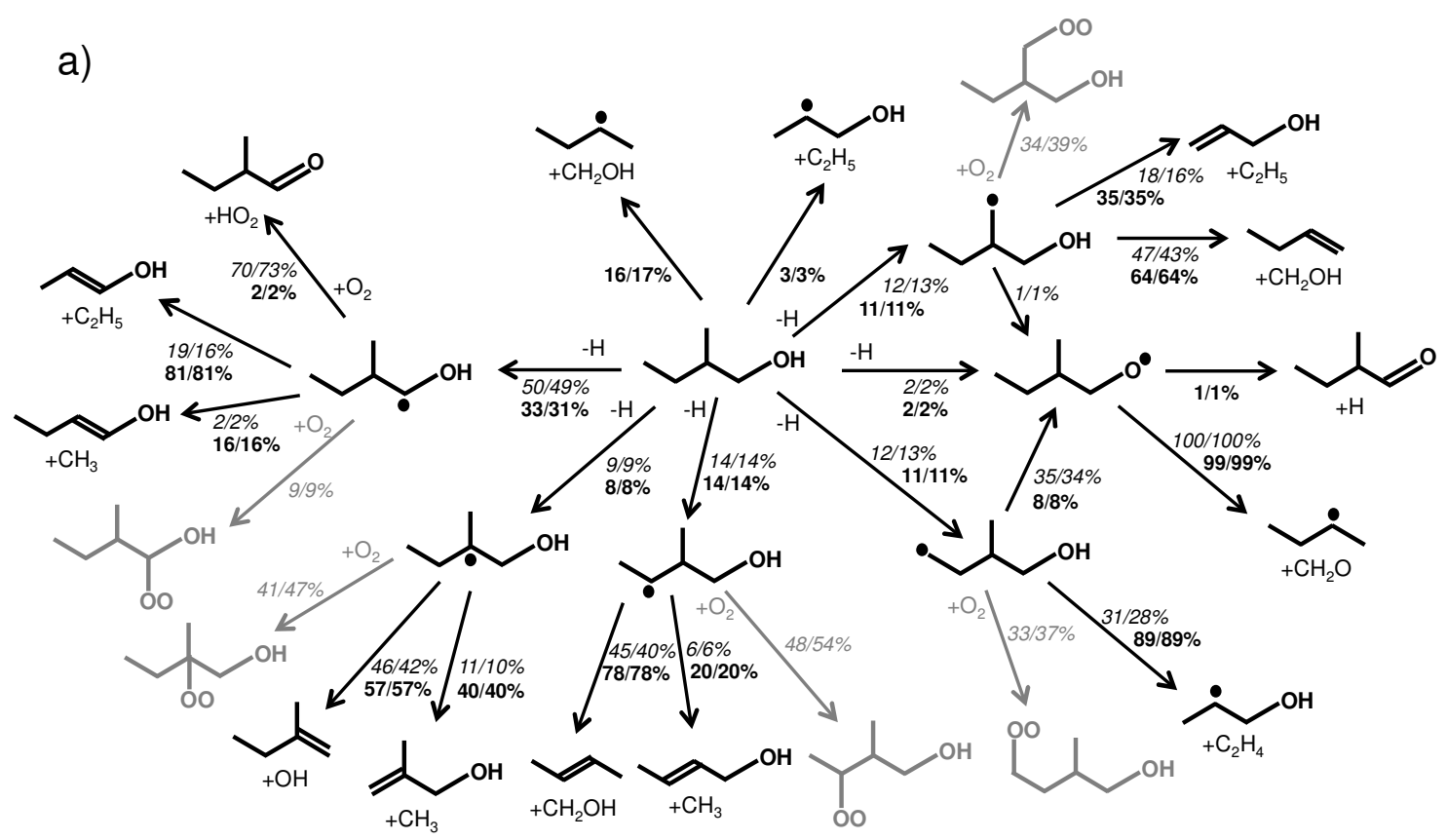




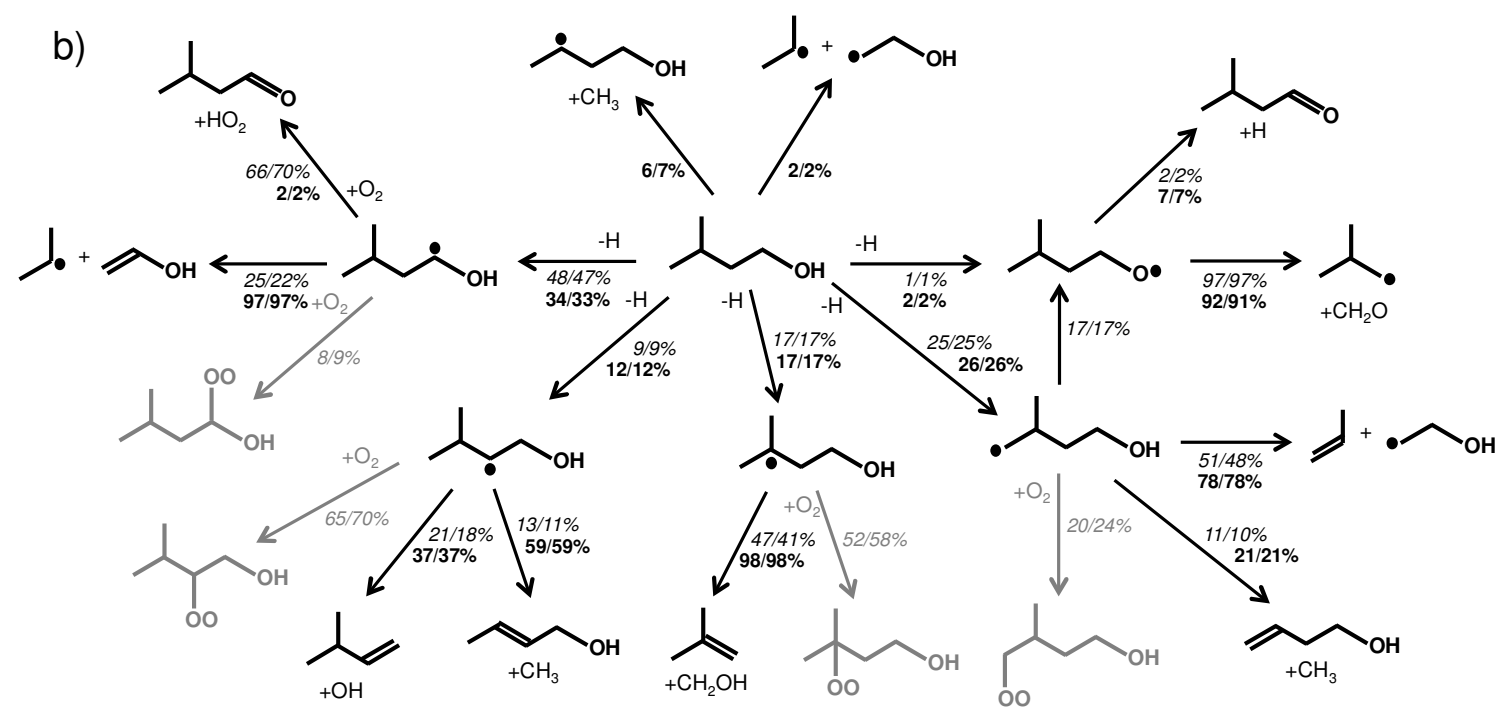

Figure 3. Reaction path analysis for a) 2-methylbutanol and b) iso-pentanol at $950 \mathrm{~K}$ (italics) and $1350 \mathrm{~K}$ (bold) under $20 \mathrm{~atm}(\phi=1.0 / 0.5)$. The reaction fluxes correspond to the time when $20 \%$ of the fuel was consumed.

Figure 4 presents the comparison of temperature and major intermediate species identified in the fuel consumption path analyses. $\mathrm{C}_{5}$ aldehyde species (2-methylbutanal and isopentanal) appear as major intermediate species in the early stage of ignition at $950 \mathrm{~K}$, while ethylene for 2-methylbutanol and propene for iso-pentanol increase rapidly before ignition occurs. However, under high-temperature conditions (1350 K), ethylene and propene remain the dominant intermediate species. As expected from the reaction path analyses, ethylene is a major intermediate species for 2-methylbutanol/air mixtures, while propene is dominant during the ignition of iso-pentanol/air mixtures. Ethylene is more reactive than propene, and the different reactivity of $\mathrm{C}_{5}$ alcohols at high-temperature conditions can be explained by this different formation of major intermediate species. Although the present detailed mechanism well reproduces the experimental ignition data qualitatively and quantitatively, further fundamental chemical kinetic studies for larger alcohols are needed to determine more accurate reaction pathways and rate constants. 

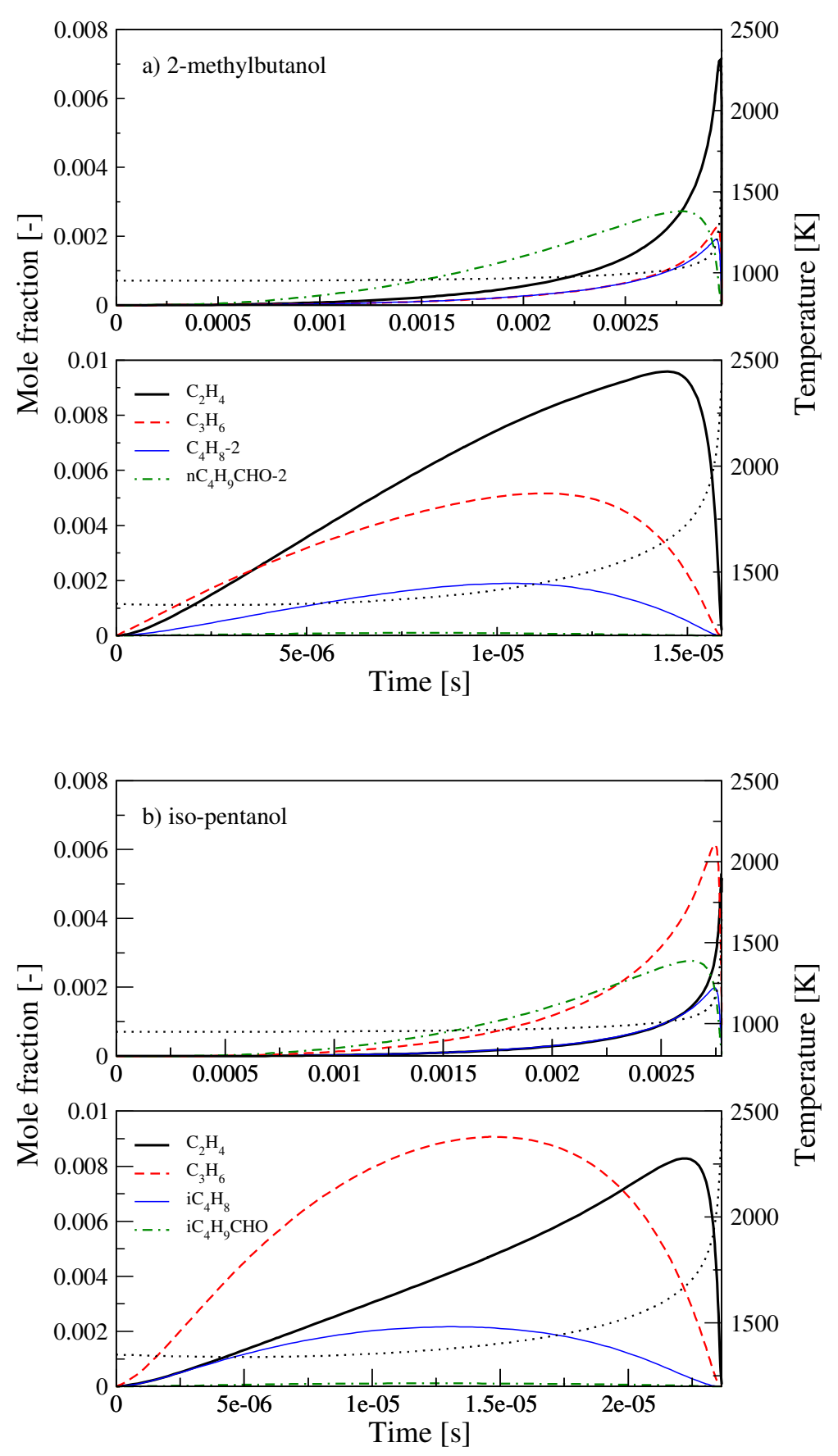

Figure 4. Predicted major intermediate species (ethylene, propene, 2-butene, iso-butene, 2methylbutanal, and iso-pentanal) and temperature profiles for a) 2-methylbutanol and b) isopentanol at $20 \mathrm{~atm}, \phi=1.0,950 \mathrm{~K}$ (top) and $1350 \mathrm{~K}$ (bottom).

\section{Heat release in an HCCI engine}


The homogeneous charge compression ignition (HCCI) has been studied extensively as an alternative internal combustion (IC) engine process to the conventional premixed SI engine and non-premixed CI engine. Yang and co-workers experimentally studied the fundamental characteristics of iso-pentanol as a fuel for HCCI engines ${ }^{37}$, while Tsujimura et al. ${ }^{44}$ simulated the results using a detailed chemical kinetic model. Their results indicated that iso-pentanol shows characteristics of intermediate temperature heat release (ITHR). HCCI engine simulations were conducted using a detailed chemical kinetic model to explain the heat release characteristics of $\mathrm{C}_{5}$ alcohols. Simulations were performed at an intake pressure $\left(\mathrm{P}_{\mathrm{in}}\right)$ of $150 \mathrm{kPa}$, a compression ratio (CR) of 14 , an engine speed of $1200 \mathrm{RPM}$, an equivalence ratio of 0.3 , and varied intake temperatures $\left(\mathrm{T}_{\text {in }}\right)$ to maintain CA50 $=368 \mathrm{CAD}$ using a single-zone homogeneous adiabatic combustion model in CHEMKIN $\mathrm{PRO}^{38}$. The simulation results of iso-octane and PRF75 are also displayed using the present detailed mechanism. Figure 5 shows the comparison of accumulated heat release and heat release rates of $\mathrm{C}_{5}$ alcohols (normalized by total heat release) with those of iso-octane and PRF75 at an early stage of heat release. $\mathrm{C}_{5}$ alcohols show relatively strong heat release prior to hot ignition. Figure 5 also indicates $C_{5}$ alcohols are more reactive than iso-octane, and these results are consistent with previous iso-pentanol studies on HCCI combustion. ${ }^{37,44}$ The required intake temperature of reactive fuels is lower than that for less reactive fuels at constant desired combustion phasing. 

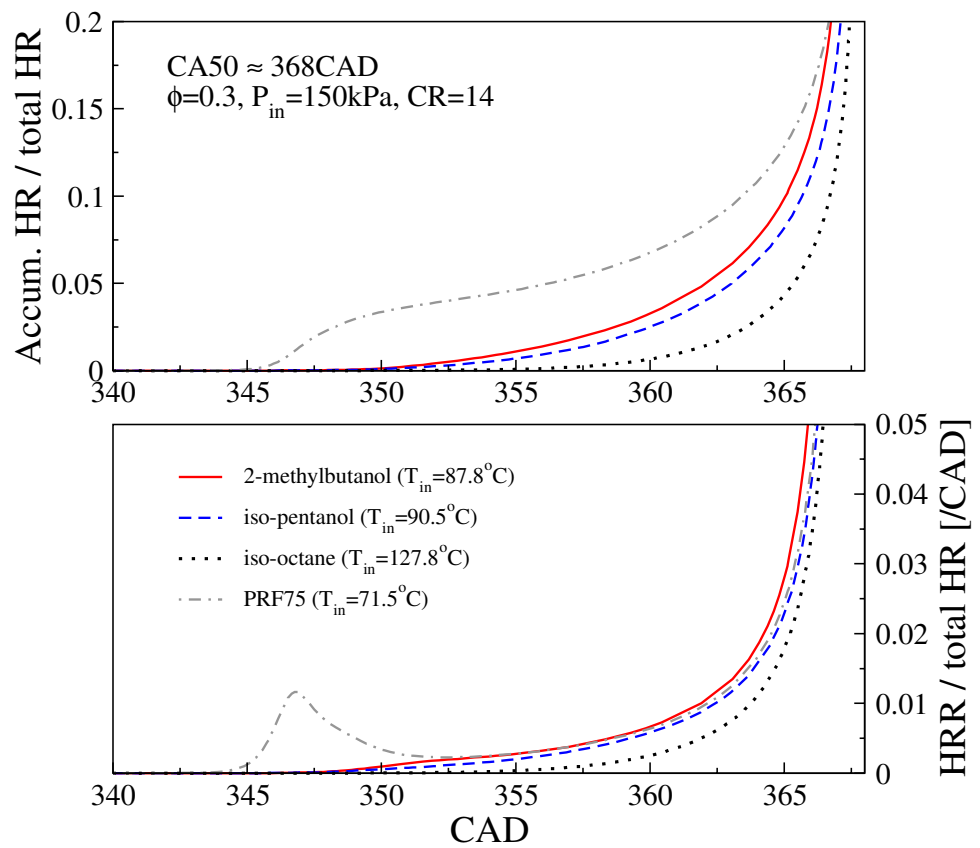

Figure 5. Comparison of accumulated heat release and heat release rate of 2-methylbutanol and iso-pentanol with those of iso-octane and PRF75. (CA50 $368 \mathrm{CAD}, \phi=0.3, \mathrm{P}_{\mathrm{in}}=150 \mathrm{kPa}$, and $\mathrm{CR}=14$ ).

To quantify the boundaries of ITHR, the heat release rate (HRR) derivative-based method $^{45}$ was employed to identify the sudden change in HRR. The start of the ITHR is defined at the point where the second derivative of the heat release is equal to zero with an upper limit set at $0.004\left(1 / \mathrm{deg}^{2}\right)$. Figure 6 presents the comparison of heat release profiles for $\mathrm{C}_{5}$ alcohols with iso-octane and PRF75 and the concentration profiles for formaldehyde $\left(\mathrm{CH}_{2} \mathrm{O}\right)$. During the ITHR period, formaldehyde is present at a significant concentration but is consumed quickly during high-temperature heat release. ${ }^{45}$ The results show that PRF75 exhibits clear lowtemperature heat release, while both 2-methylbutanol and iso-pentanol display considerably more prominent ITHR behavior than iso-octane under the given conditions. The rate of temperature rise prior to hot ignition is important for maintaining the stability of HCCI 
combustion, wherein retarding combustion phasing by increasing ITHR allows for a more moderate rate of pressure increase while avoiding misfire. ${ }^{46}$

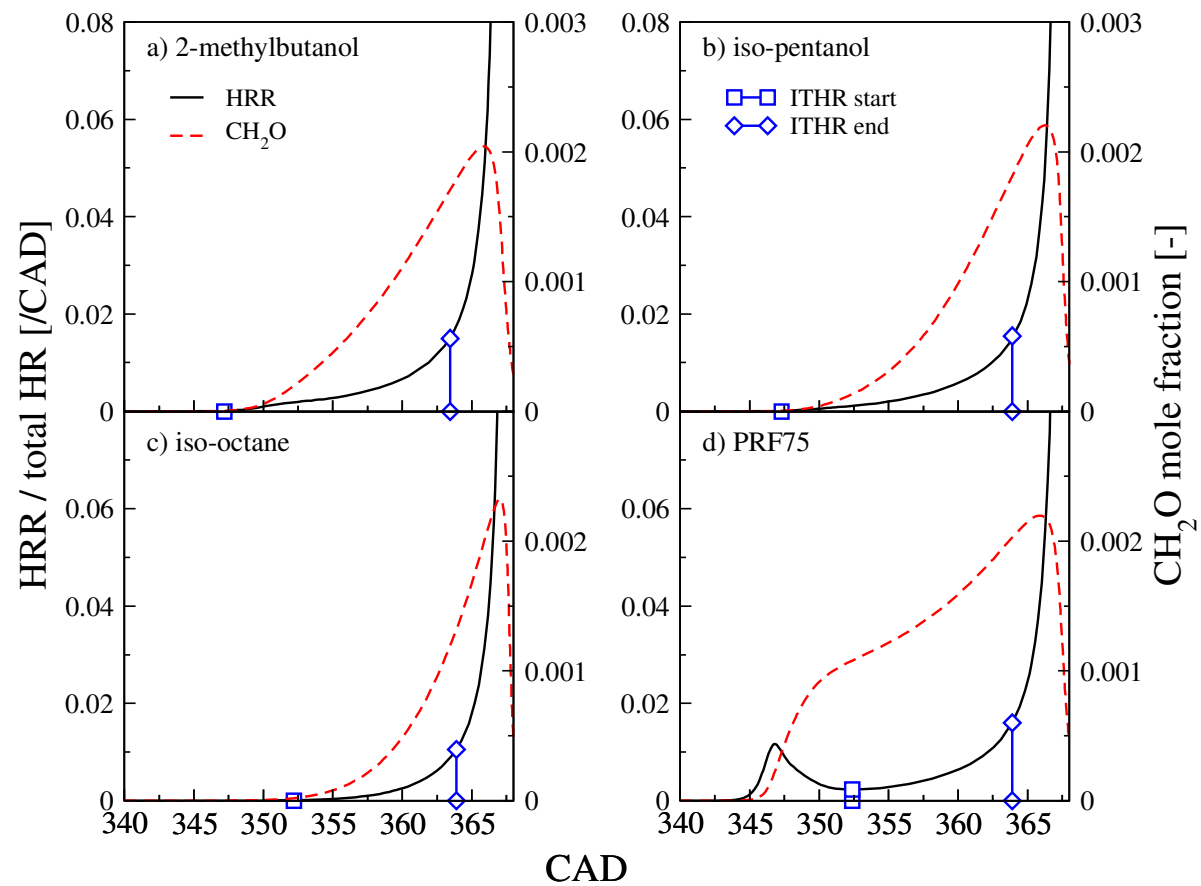

Figure 6. Comparison of ITHR boundaries of 2-methylbutanol and iso-pentanol with those of iso-octane and PRF75. (CA50 $368 \mathrm{CAD}, \phi=0.3, \mathrm{P}_{\mathrm{in}}=150 \mathrm{kPa}$, and $\left.\mathrm{CR}=14\right)$. Concentration profiles of formaldehyde are also presented.

Figure 7 presents the dominant reactions of $\mathrm{C}_{5}$ alcohols contributing to the heat release rate at $8^{\circ}$ before CA50 to provide insight into the ITHR (930 950K). To simplify the analysis, $\mathrm{H}$-atom abstraction reactions by $\mathrm{OH}$ radicals and fuel radical reactions with $\mathrm{O}_{2}$ were grouped together to calculate the sum of heat release. The results indicate that the most important reactions contributing to the rate of heat release are the reactions between fuel radicals and molecular oxygen $\left(\mathrm{R}+\mathrm{O}_{2}\right.$ reactions), as well as $\mathrm{H}$-atom abstraction by $\mathrm{OH}$ radicals (fuel $+\mathrm{OH}=\mathrm{R}+\mathrm{H}_{2} \mathrm{O}$ reactions). In addition, hydrogen peroxide formation paths by the recombination of $\mathrm{HO}_{2}$ radicals via $\mathrm{H}+\mathrm{O}_{2}$ reaction are also important for heat release during 
ITHR, but the rapid decomposition reaction of $\mathrm{H}_{2} \mathrm{O}_{2}$ to $\mathrm{OH}$ radicals is endothermic to partially reduce the heat release from the above reactions at relatively high temperatures (930 950K).

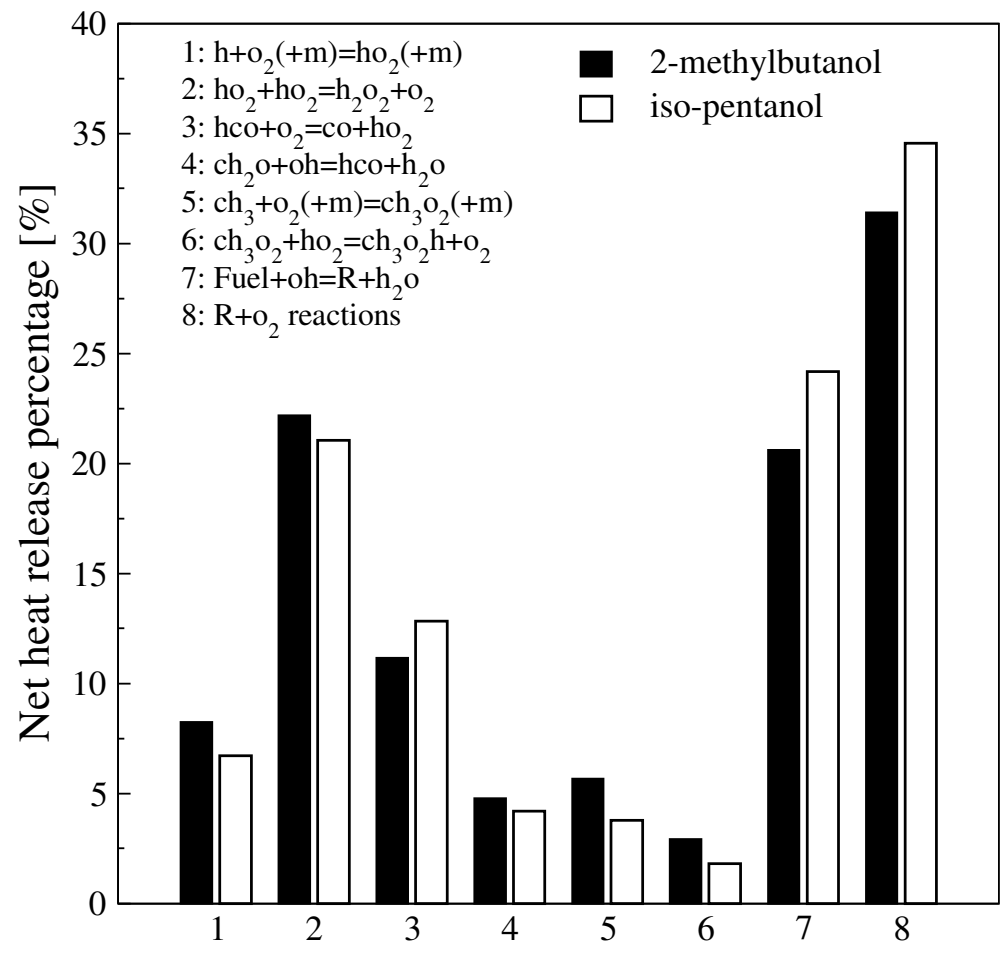

Figure 7. Net heat release by elementary reactions of $\mathrm{C}_{5}$ alcohols as a percentage of ITHR $8^{\circ}$ before CA50. (CA50 $368 \mathrm{CAD}, \phi=0.3, \mathrm{P}_{\text {in }}=150 \mathrm{kPa}$, and $\mathrm{CR}=14$ ).

\section{Mechanism reduction with $D R G X$}

The direct relation graph (DRG) with expert knowledge (DRGX) method $^{47,48}$ was used to develop a skeletal mechanism for HCCI engine combustion simulations. The DRG ${ }^{49}$ method is based on the observation that weakly coupled species during combustion process can be eliminated. The first step in DRG is to quantify species coupling by the pair-wise error, $r_{\mathrm{AB}}$, induced to a species A by the elimination of another species B for a given temperature and species concentrations. Figure 8 shows a typical species relations in a DRG. The arrow shows 
the direction of dependence with the line weight indicating the relative importance. It is seen that A depends on B, but B does not depends on A. Moreover, species B and D are strongly coupled to form the dependent set $\{\mathrm{B}, \mathrm{D}\}$ of $\mathrm{A}$ and have to be kept for correct prediction of $\mathrm{A}$. However, species $\mathrm{C}, \mathrm{E}$ and $\mathrm{F}$ can be eliminated because they are not required either A or any dependent set $\{B, D\}$ of $A$.

$T_{A B} \equiv \frac{\max _{i}\left|v_{A i} \omega_{i} \delta_{B i}\right|}{\max _{i}\left|v_{A i} \omega_{i}\right|} \delta_{B i}=\left\{\begin{array}{l}1, \text { if the ith reaction involves } B \\ 0, \text { otherwise }\end{array}\right.$

$\omega_{i}:$ net reaction rate of the ith reaction

$v_{A i}$ : stoichiometric coefficient of species $\mathrm{A}$ in the $i$ th reaction.

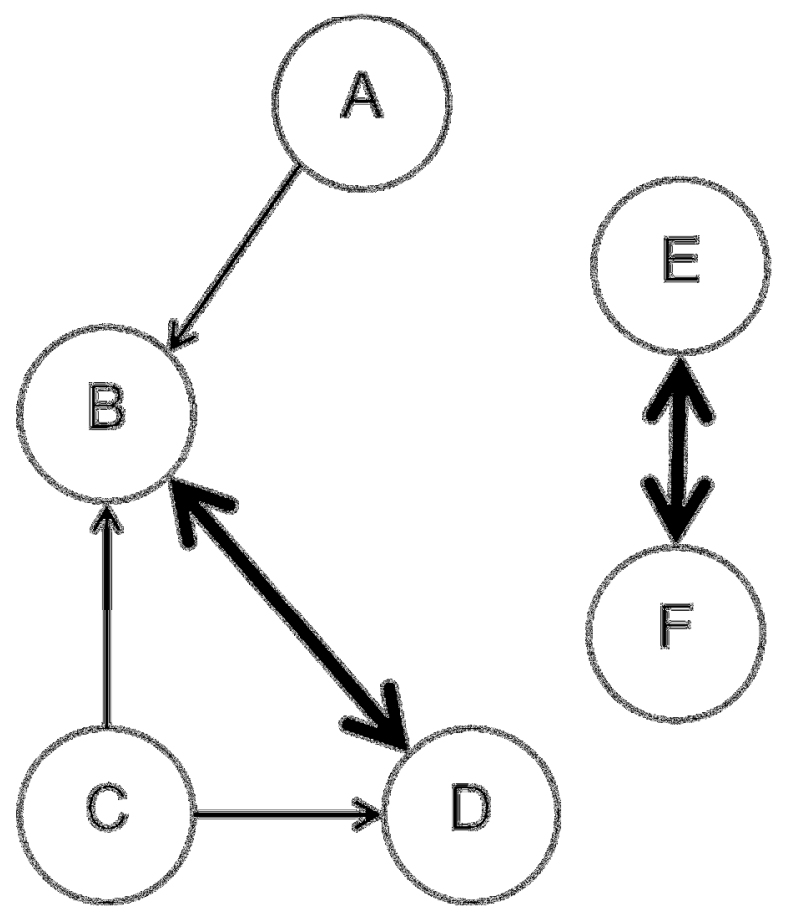

Figure 8. Typical species relation in a direct relation graph.

Compared to the original DRG, DRGX allows for species-specific error control employing a revised depth-first search (RDFS). ${ }^{50}$ Species-specific error tolerances can be used for selected species with small uncertainties for associated reactions. Any species B having larger $r_{\mathrm{AB}}$ than specified error tolerance will be retained in the skeletal mechanism, while other 
species are treated using a default error tolerance. Such expert-specified species-specific information renders it possible to develop a highly accurate skeletal mechanism for heat release or species concentrations of interest.

Here, we performed a DRGX on sampled data from auto-ignition and a perfectly stirred reactor (PSR) model in a parameter range relevant to our $\mathrm{HCCI}$ combustion for $\mathrm{C}_{5}$ alcohols and PRF75. The reduction covers pressures of 1,20, and $40 \mathrm{~atm}$, equivalence ratios between 0.3 and 1.0, initial temperatures for ignition from 650 to $1400 \mathrm{~K}$, and an inlet temperature of $400 \mathrm{~K}$ for PSR. By specifying an error tolerance of 0.05 for temperature, 0.2 for $\mathrm{H}$ and $\mathrm{OH}$ radicals, and a default error tolerance of 0.45 , the resulting skeletal mechanism consists of 631 species and 3233 reaction steps from the detailed mechanism by assigning 3 independent fuels (2-methylbutanol, iso-pentanol, and PRF75) as input parameters. The comparisons of laminar flame speed and jetstirred reactor (JSR) species profiles using the skeletal mechanism are provided in the Supplementary material.

\section{Skeletal mechanism for HCCI simulation}

Before using the skeletal mechanism under HCCI engine combustion conditions, the skeletal mechanism was compared with the detailed mechanism. Figure 9 shows the ignition delay times of a) 2-methylbutanol, b) iso-pentanol, and c) PRF75 in air at 20 and 40 atm. Simulations were conducted using the adiabatic constant volume homogenous reactor model in CHEMKIN $\mathrm{PRO}^{38}$. The skeletal mechanism is in excellent agreement with the detailed mechanism covering pressures of 20 and 40 atm at equivalence ratios of $0.3,0.5$, and 1.0, which corresponds to HCCI engine simulation conditions. 

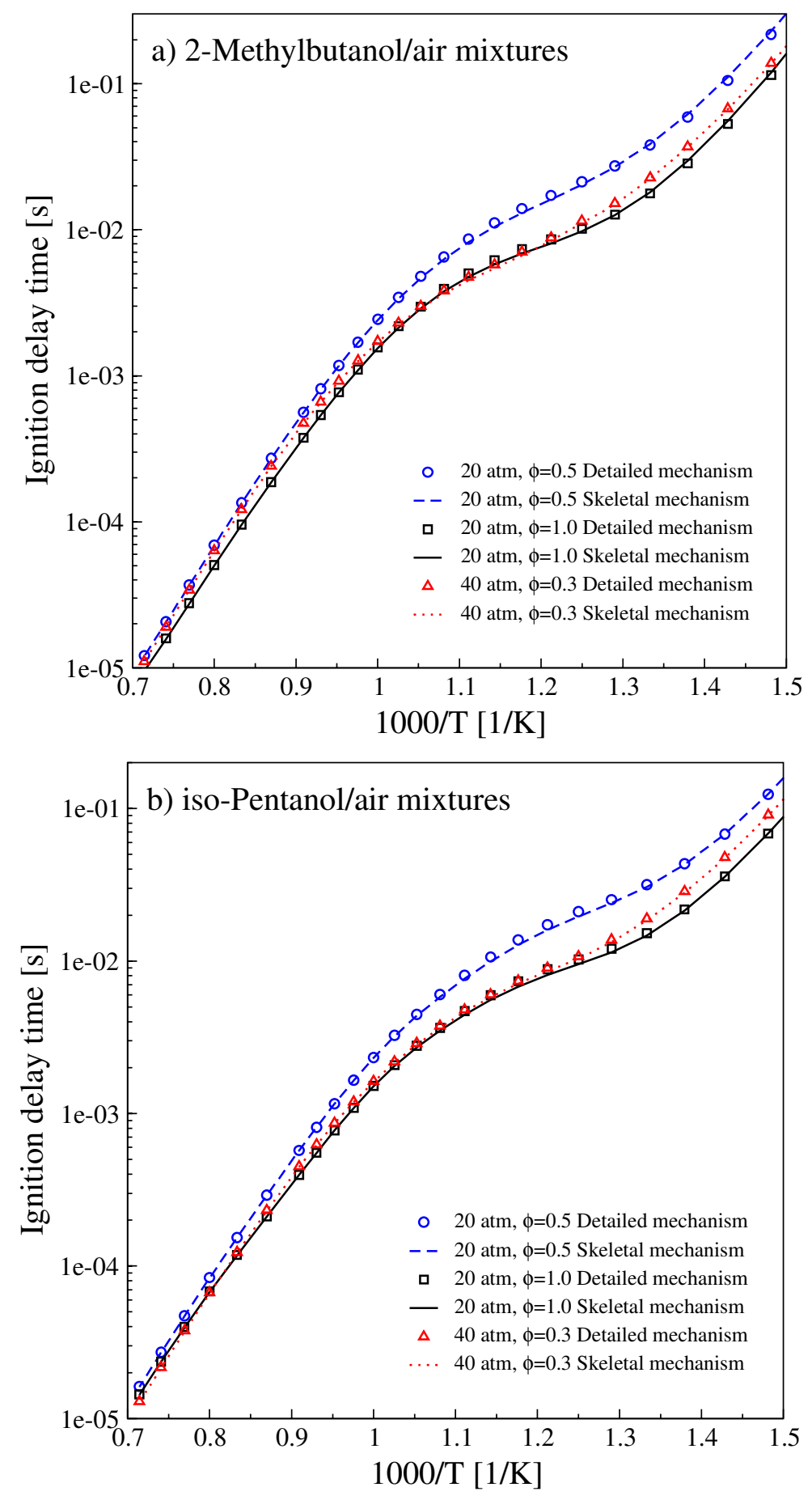


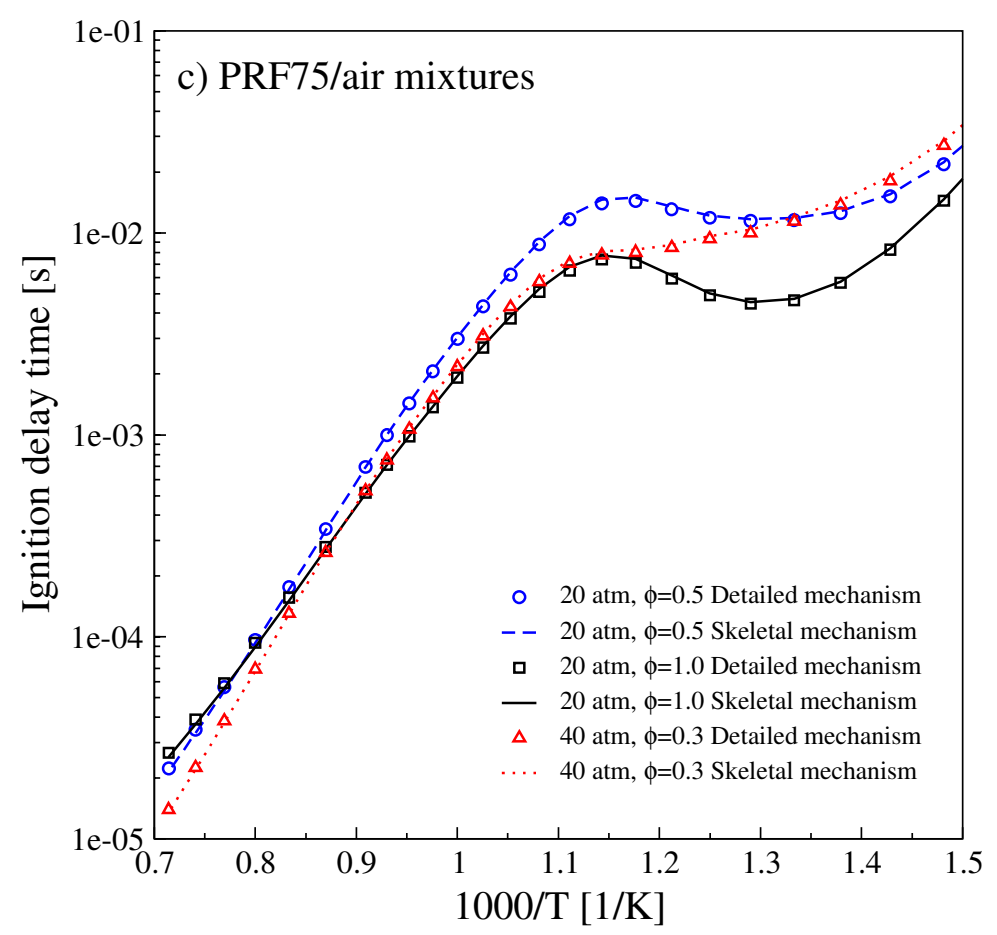

Figure 9. Comparison between detailed (dashed lines) and skeletal (solid lines) mechanisms for ignition delay times of a) 2-methylbutanol, b) iso-pentanol, and c) PRF75.

HCCI engine simulations were performed at the same conditions of the above mentioned HCCI simulation (intake pressure $\left(\mathrm{P}_{\text {in }}\right): 150 \mathrm{kPa}, \mathrm{CR}: 14$, engine speed : $1200 \mathrm{RPM}$, equivalence ratio : 0.3 , and $\mathrm{CA} 50=368 \mathrm{CAD}$ ) using the skeletal mechanism and the results were compared with those of the detailed mechanism. All simulations use a single-zone homogeneous adiabatic combustion model in CHEMKIN PRO ${ }^{38}$. Figure 10 shows the comparison of pressure, temperature, and heat release rates (normalized by total heat release) of $\mathrm{C}_{5}$ alcohols and PRF75 between skeletal and detailed mechanisms. The results show good agreement between skeletal and detailed mechanisms including rates of heat release, pressure, and temperature histories for a given combustion phasing $(\mathrm{CA} 50=368 \mathrm{CAD})$. However, intake temperatures are required to decrease by $2.4^{\circ} \mathrm{C}$ for 2 -methylbutanol $\left(\mathrm{T}_{\mathrm{in}}=85.4^{\circ} \mathrm{C}\right)$ and $3.4^{\circ} \mathrm{C}$ for $i s o$-pentanol $\left(\mathrm{T}_{\mathrm{in}}=87.1^{\circ} \mathrm{C}\right)$, and increase by $2.1^{\circ} \mathrm{C}$ for PRF75 $\left(\mathrm{T}_{\mathrm{in}}=73.6^{\circ} \mathrm{C}\right)$ to obtain the given combustion phasing. The skeletal 
mechanism successfully captures the ITHR characteristics of $\mathrm{C}_{5}$ alcohols and LTHR of PRF75. The dominant reactions contributing to heat release at the early stage of ignition are the fuel radical reactions with molecular oxygen $\left(\mathrm{R}+\mathrm{O}_{2}\right.$ reactions) and the hydrogen peroxide $\left(\mathrm{H}_{2} \mathrm{O}_{2}\right)$ formation reactions according to previous analysis.
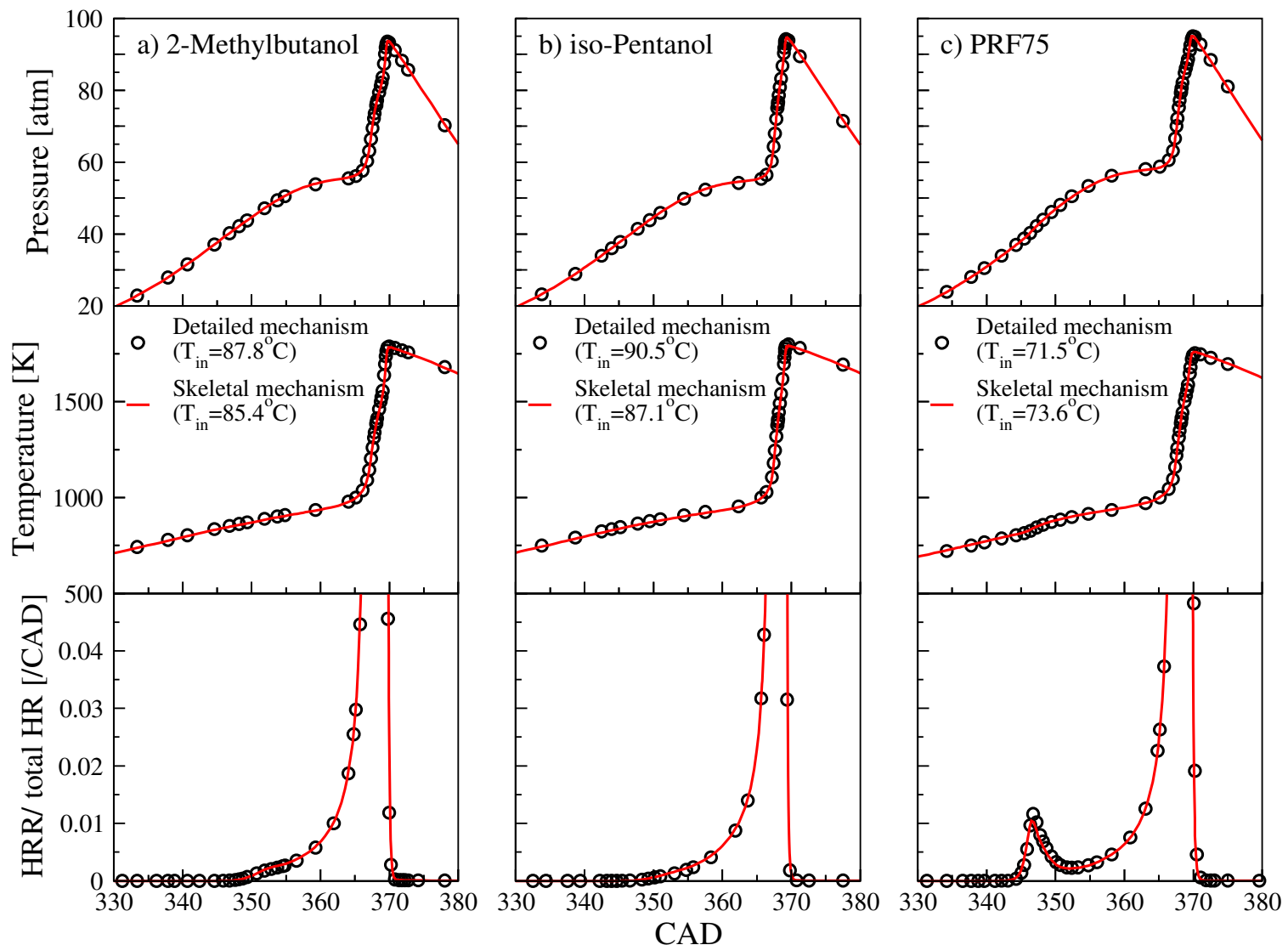

Figure 10. Comparison of detailed (symbols) and skeletal (lines) mechanisms for pressure, temperature, and heat release rate of a) 2-methylbutanol, b) iso-pentanol, and c) PRF75. $\left(\mathrm{CA} 50 \approx 368 \mathrm{CAD}, \phi=0.3, \mathrm{P}_{\mathrm{in}}=150 \mathrm{kPa}\right.$, and $\left.\mathrm{CR}=14\right)$.

To examine the capability for retarding combustion phasing, the intake temperature sensitivity test was conducted using the skeletal mechanism by sweeping $T_{\text {in }}$ from a temperaturecausing advanced combustion phasing to a temperature-causing retarded combustion phasing. Figure 11A shows the comparison of sensitivities of $\mathrm{C}_{5}$ alcohols to intake temperature. 
Simulations were performed at intake pressures $\left(\mathrm{P}_{\text {in }}\right)$ of $150 \mathrm{kPa}$, a CR of 14 , an engine speed of 1200 RPM, and an equivalence ratio of 0.3. As the intake temperature $\left(T_{\text {in }}\right)$ decreases, combustion phasing is retarded and becomes more sensitive to changes in $\mathrm{T}_{\mathrm{in}}$. Fuels with stronger ITHRs will be less sensitive to $T_{\text {in }}$ change for any given CA50 due to the high rate of temperature rise before hot ignition and will be less affected by random variations in combustion stability. ${ }^{37}$ The combustion phasing of iso-pentanol is later than that of 2-methylbutanol at lowest intake temperature $\left(85^{\circ} \mathrm{C}\right)$ because iso-pentanol is less reactive at relevant constant volume ignition delay conditions $(\mathrm{T}=850 \mathrm{~K}$ at $40 \mathrm{~atm})$, as shown in Figure 12. The effects of intake pressure were also investigated using the skeletal mechanism by changing $\mathrm{P}_{\text {in }}$. In previous studies $^{51,52}$, gasoline has shown enhanced ITHR with boosted intake pressure, while ethanol shows no dependence on intake pressure. Figure 11B displays the comparison of intake temperatures of $\mathrm{C}_{5}$ alcohols to maintain constant combustion phasing with various intake pressures. Simulations were performed at a CR of 14, an engine speed of 1200 RPM, and an equivalence ratio of 0.3 and varied $T_{\text {in }}$ to maintain CA50 $=368$ CAD. In this study, the $P_{\text {in }}$ sweep was conducted at $\mathrm{P}_{\text {in }}=110-190 \mathrm{kPa}$. Results show that the required intake temperature decreases as $P_{\text {in }}$ increases due to the increased reactivity caused by increasing pressure. Figure $11 \mathrm{C}$ shows the comparison of intake temperatures at constant CA50 with various engine speeds. $T_{i n}$ were varied to maintain a constant CA50 with changing engine speed at $P_{\text {in }}$ of $150 \mathrm{kPa}$, a CR of 14 , and an equivalence ratio of 0.3 . The $T_{\text {in }}$ was increased to maintain the combustion phasing at higher engine speeds, and the simulated trend is consistent with experimental engine measurements ${ }^{37}$. 

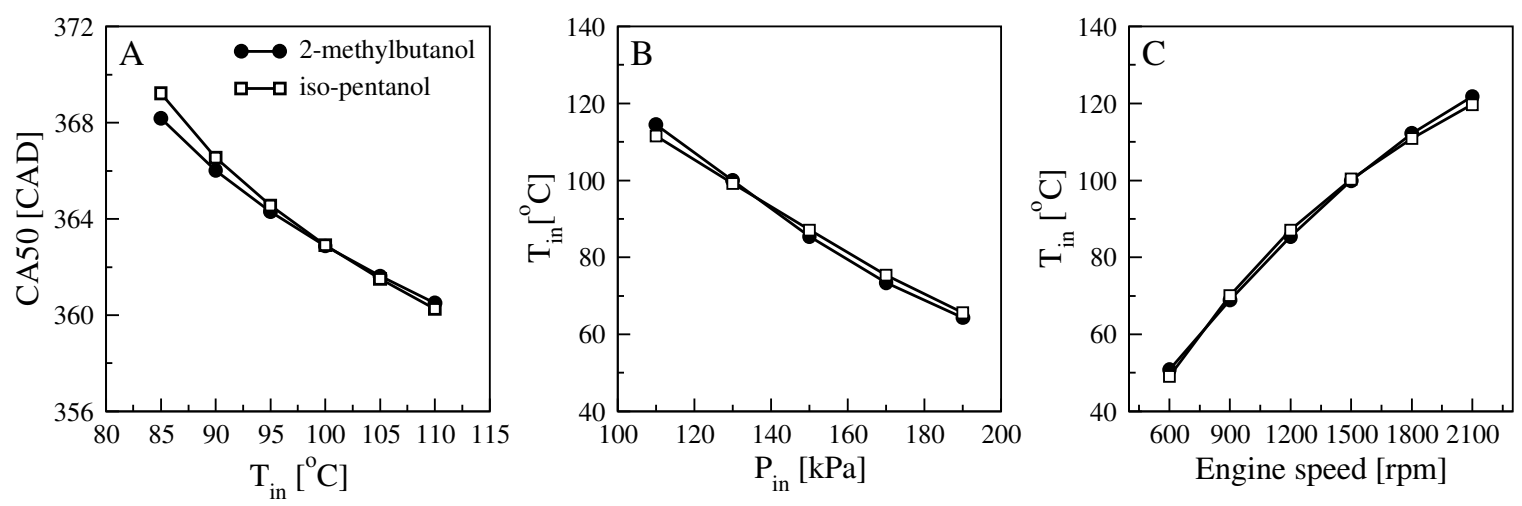

Figure 11. Sensitivity of A) intake temperature, B) pressure, and C) engine speed of $\mathrm{C}_{5}$ alcohols. ( $\phi=0.3$ and $C R=14)$.

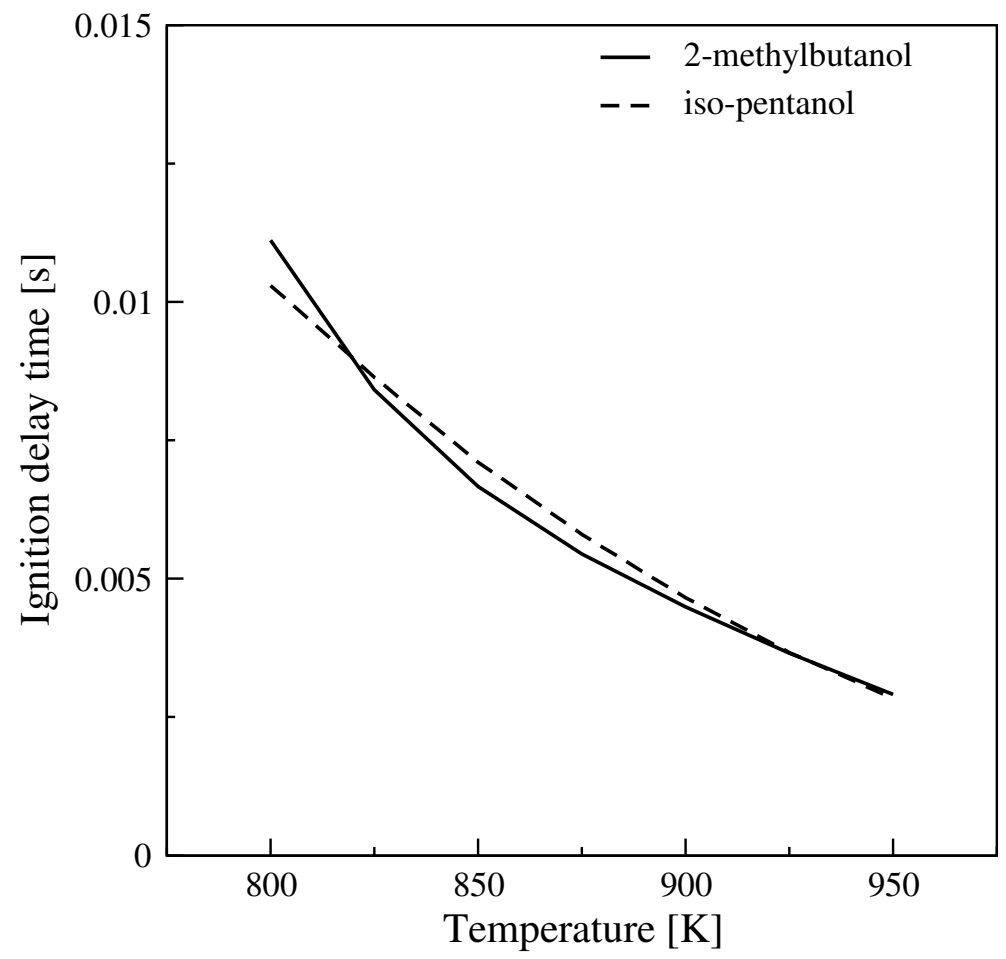

Figure 12. Ignition delay times of $\mathrm{C}_{5}$ alcohols at relevant HCCI conditions (40 atm, $\phi=0.3$ ).

Figure 13 shows the evolution of pressure and accumulated heat release to evaluate the effect of $\mathrm{C}_{5}$ alcohol addition to PRF75/air mixtures in HCCI combustion. Simulations were performed at an intake pressure $\left(\mathrm{P}_{\mathrm{in}}\right)$ of $150 \mathrm{kPa}$, a compression ratio $(\mathrm{CR})$ of 14 , an engine speed of 1200 RPM, an equivalence ratio of 0.3 , and intake temperatures $\left(\mathrm{T}_{\text {in }}\right)$ of $90{ }^{\circ} \mathrm{C}$ using a single- 
zone homogeneous adiabatic combustion model in CHEMKIN PRO ${ }^{38}$. As expected, combustion phasing is retarded as alcohol addition increases due to the corresponding increase in octane number, and the maximum pressure decreases as alcohol addition increases. The results also show that low-temperature heat release decreases with increasing addition of $\mathrm{C}_{5}$ alcohols.

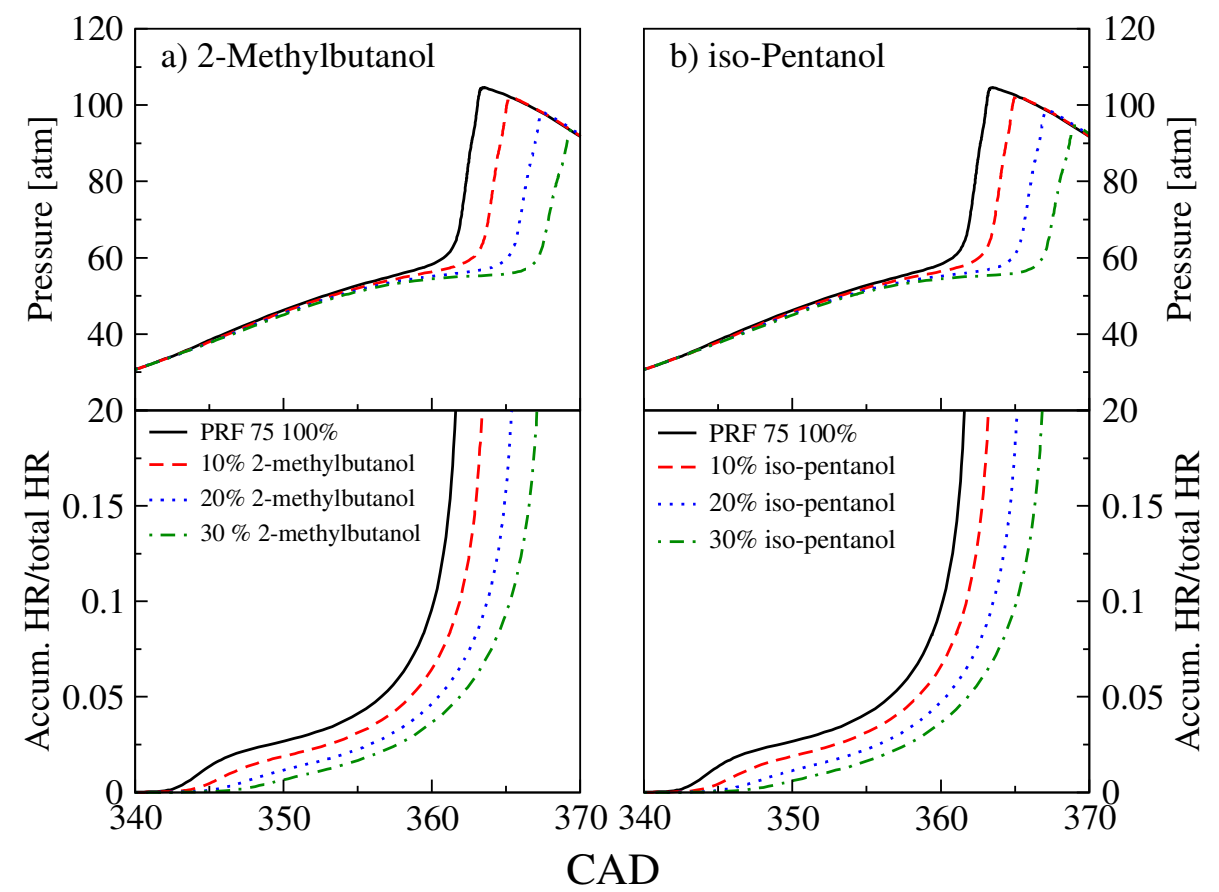

Figure 13. Comparison of pressure and accumulated heat release of PRF75 with $\mathrm{C}_{5}$ alcohol addition. (CA50 $368 \mathrm{CAD}, \phi=0.3, \mathrm{P}_{\text {in }}=150 \mathrm{kPa}$, and $\mathrm{CR}=14$ ).

To highlight the effect of alcohol addition on LTHR, heat release rates (normalized by total heat release), formaldehyde $\left(\mathrm{CH}_{2} \mathrm{O}\right)$, and hydroperoxyl radical $\left(\mathrm{HO}_{2}\right)$ concentrations at cool flame zone are presented in Figure 14. Formaldehyde starts to accumulate during the LTHR period and present at a significant concentration during ITHR. ${ }^{45}$ The formation of hydrogen peroxide $\left(\mathrm{H}_{2} \mathrm{O}_{2}\right)$ by the recombination reactions of $\mathrm{HO}_{2}$ radicals via $\mathrm{H}+\mathrm{O}_{2}$ reaction contributes to heat release during LTHR. The results show a significant decrease of the peak of LTHR when $30 \% \mathrm{C}_{5}$ alcohol is blended to PRF75. Figure 14 also shows the decrease in $\mathrm{HO}_{2}$ formation during 
LTHR for $\mathrm{C}_{5}$ alcohol addition to PRF75, and these blended fuels have relatively strong ITHR characteristics.
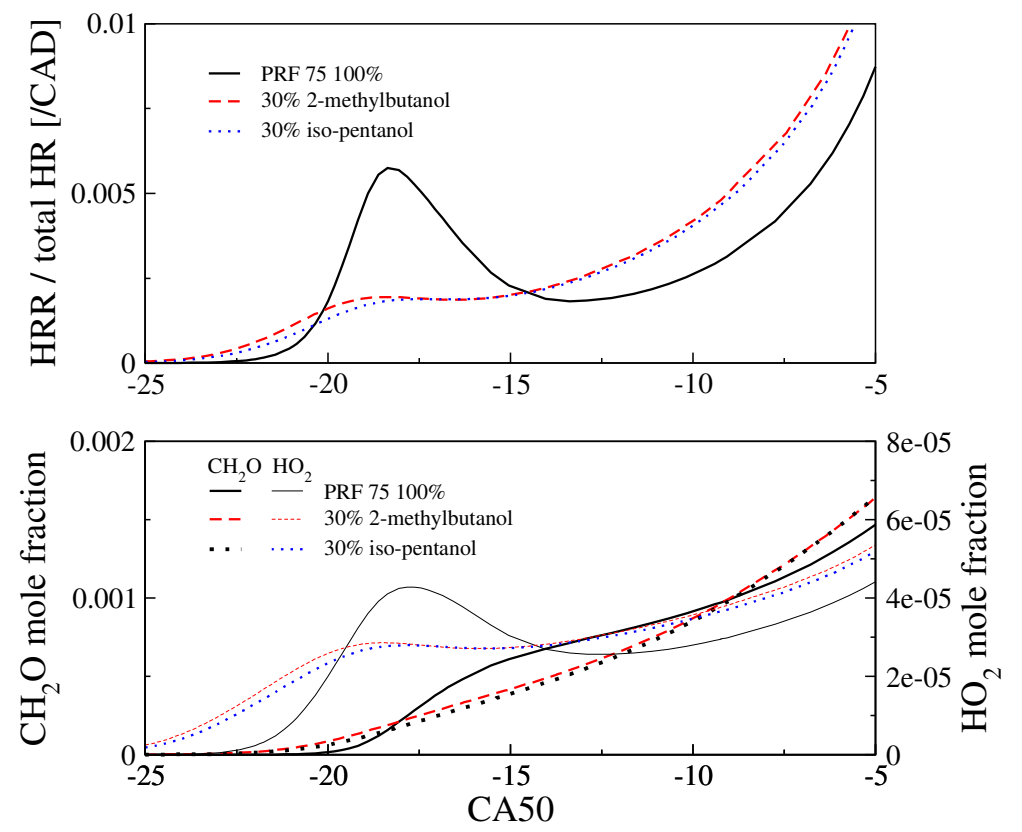

Figure 14. Comparison of heat release rate and intermediate species of PRF75 with $\mathrm{C}_{5}$ alcohol addition at cool flame zone.

The intake temperature sensitivity test for PRF75 with $\mathrm{C}_{5}$ alcohols was conducted to investigate the effect of alcohol addition by sweeping $T_{\text {in }}$ from an advanced combustion phasing to a retarded combustion phasing, as shown in Figure 15. Simulations were performed at intake pressures $\left(\mathrm{P}_{\mathrm{in}}\right)$ of $150 \mathrm{kPa}$, a CR of 14 , an engine speed of $1200 \mathrm{RPM}$, and an equivalence ratio of 0.3. As the intake temperature $\left(\mathrm{T}_{\text {in }}\right)$ decreases, combustion phasing is retarded and becomes more sensitive to changes in intake temperature. Figure 15 also shows the effect of alcohol addition to delay the main combustion at lower intake temperatures. The effect of alcohol addition on combustion phasing disappears as temperature increases near $135{ }^{\circ} \mathrm{C}$, where the reactivity of $\mathrm{C}_{5}$ alcohols are close to those of PRFs (relevant to $950 \mathrm{~K}$ at $40 \mathrm{~atm}$ ). As discussed 
previously, the reactivity of iso-pentanol is less than that of 2-methylbutanol at lowest intake temperature $\left(75^{\circ} \mathrm{C}\right)$.

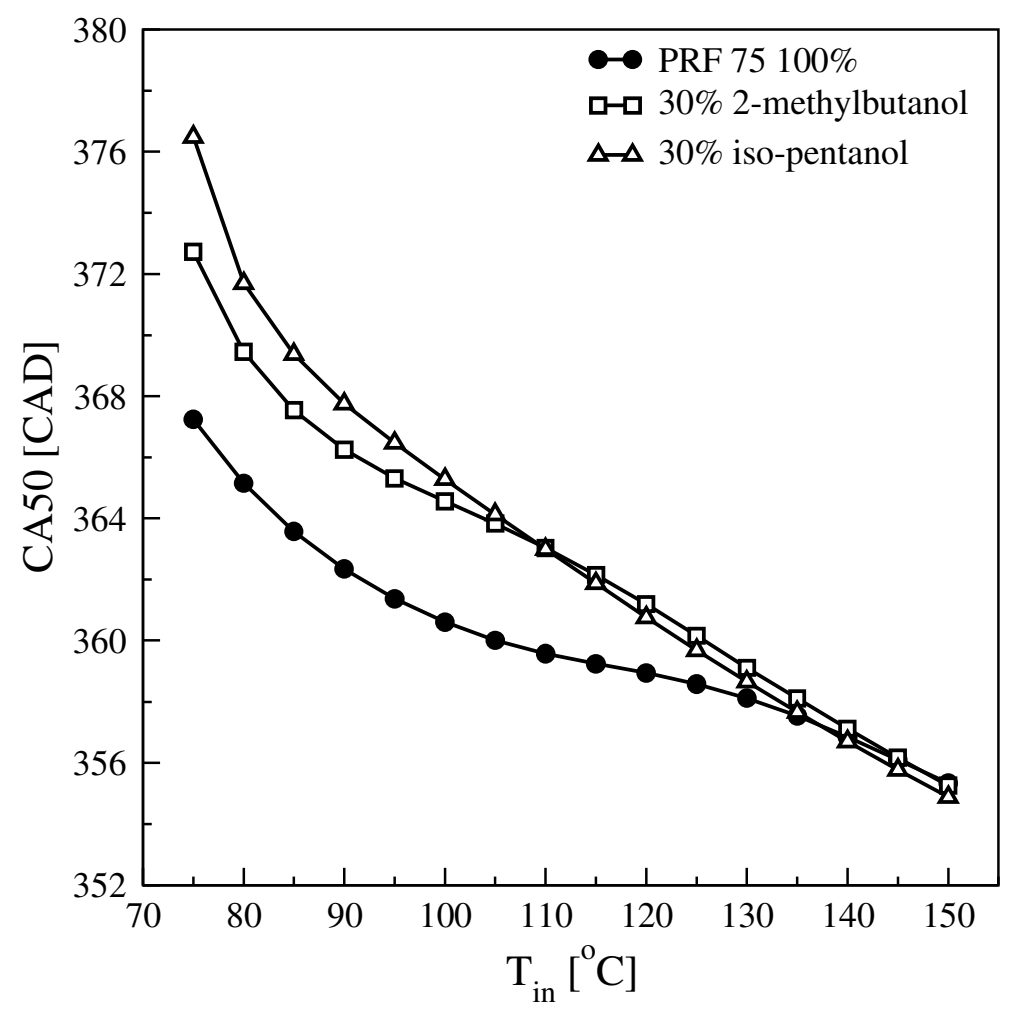

Figure 15. Comparison of intake temperature sensitivity of PRF75 with $\mathrm{C}_{5}$ alcohol addition. $\left(\mathrm{CA} 50 \approx 368 \mathrm{CAD}, \phi=0.3, \mathrm{P}_{\mathrm{in}}=150 \mathrm{kPa}\right.$, and $\left.\mathrm{CR}=14\right)$.

\section{Conclusion}

The ignition delay times of two $\mathrm{C}_{5}$ alcohol isomers were compared with those of PRFs. Overall, ignition delay time of $\mathrm{C}_{5}$ alcohols is slightly faster than for either PRF (heptane and isooctane) at intermediate-temperature regions, but slower than iso-octane in the low-temperature region due to a lack of NTC behavior. The ignition delay time of 2-methylbutanol/air mixtures is similar to that of iso-pentanol/air mixtures at intermediate temperatures, while the ignition delay times and overall activation energy of 2-methylbutanol are lower than iso-pentanol at high temperatures. Reaction path analyses were conducted at intermediate- and high-temperature 
conditions using a detailed chemical kinetic model to identify the important reactions controlling the ignition of both $\mathrm{C}_{5}$ alcohol fuels.

HCCI simulations were performed to better understand the characteristics of heat release of $\mathrm{C}_{5}$ alcohols. The detailed mechanism predicts that $\mathrm{C}_{5}$ alcohols show relatively strong reactions at intermediate temperatures prior to hot ignition, and that both the $\mathrm{C}_{5}$ alcohol fuels have higher HCCI reactivity than does iso-octane under the given conditions.

A new skeletal mechanism for HCCI combustion was developed using a direct relation graph with expert knowledge (DRGX) for two $\mathrm{C}_{5}$ alcohols and PRF75. The resulting skeletal mechanism was tested against various HCCI engine combustion conditions, including intake pressure, intake temperature, and engine speed, to better understand the combustion properties of these $\mathrm{C}_{5}$ alcohols in an $\mathrm{HCCI}$ engine. Combustion phasing is retarded and becomes more sensitive as intake temperature decreases and reactivity is increased with increased intake pressure. The intake temperature requirement was increased at higher engine speeds to maintain constant combustion phasing. The reactivity of iso-pentanol is lower than that of 2methylbutanol in $\mathrm{HCCI}$ combustion under low intake temperature conditions In addition, $\mathrm{C}_{5}$ alcohol addition to PRF75 in HCCI combustion leads to a significant decrease of LTHR and a delay the main combustion at lower intake temperatures. 


\section{AUTHOR INFORMATION}

\section{Corresponding Author}

*E-mail: sungwoo.park@kaust.edu.sa

\section{ACKNOWLEDGMENT}

Research reported in this publication was supported by competitive research funding from King Abdullah University of Science and Technology (KAUST). The authors acknowledge support

from the Clean Combustion Research Center under the Future Fuels research program and from Saudi Aramco under the FUELCOM program. 


\section{REFERENCES}

1. Sarathy, S. M.; Oßwald, P.; Hansen, N.; Kohse-Höinghaus, K., Alcohol combustion chemistry. Prog. Energy Combust. Sci. 2014, 44, 40-102.

2. Agarwal, A., Biofuels (alcohols and biodiesel) applications as fuels for internal combustion engines. Prog. Energy Combust. Sci. 2007, 33, 233-271.

3. Moss, J. T.; Berkowitz, A. M.; Oehlschlaeger, M. A.; Biet, J.; Warth, V.; Glaude, P. A.; Battin-Leclerc F., An experimental and kinetic modeling study of the oxidation of the four isomers of butanol. J. Phys. Chem. A 2008, 112, 10843-10855.

4. Sarathy, S. M.; Thomson, H. J.; Togbé, C.; Dagaut, P.; Halter, F.; Mounaim-Rousselle, C., An experimental and kinetic modeling study of n-butanol combustion. Combust. Flame 2009, 156, 852-864.

5. Black, G.; Curran, H. J.; Pichon, S.; Simmie, J. M.; Zhukov, V., Bio-butanol: Combustion properties and detailed chemical kinetic model. Combust. Flame 2010, 157, 363-373.

6. Dagaut, P.; Sarathy, S. M.; Thomson, M. J., A chemical kinetic study of n-butanol oxidation at elevated pressure in a jet stirred reactor. Proc. Combust. Inst. 2009, 32, 229237.

7. Togbé, C.; Mzé-Ahmed, A.; Dagaut, P., Kinetics of oxidation of 2-butanol and isobutanol in a jet-stirred reactor: experimental study and modeling investigation. Energy Fuels 2010, $24,5244-5256$. 
8. Grana, R.; Frassoldati, A.; Faravelli, T.; Niemann, U.; Ranzi, E.; Seiser, R.; Cattolica, R.; Seshadri, K., An experimental and kinetic modeling study of combustion of isomers of butanol. Combust. Flame 2010, 157, 2137-2154.

9. Oßwald, P.; Güldenberg, H.; Kohse-Höinghaus, K.; Yang, B.; Yuan, T.; Qi, F., Combustion of butanol isomers - A detailed molecular beam mass spectrometry investigation of their flame chemistry. Combust. Flame 2011, 158, 2-15.

10. Hansen, N.; Harper, M. R.; Green, W. H., High-temperature oxidation chemistry of nbutanol - experiments in low-pressure premixed flames and detailed kinetic modeling. Phys. Chem. Chem. Phys. 2011, 13, 20262-20274.

11. Lefkowitz, J. K.; Heyne, J. S.; Won, S. H.; Dooley, S.; Kim, H. H.; Hass, F. M.; Jahangirian, S.; Dryer, F. L.; Ju, Y., A chemical kinetic study of tertiary-butanol in a flow reactor and a counterflow diffusion flame. Combust. Flame 2012, 159, 968-978.

12. Sarathy, S. M.; Vranckx, S.; Yasunaga, K.; Mehl, M.; Oßwald, P.; Metcalfe, W. K.; Westbrook, C. K.; Pitz, W. J.; Kohse-Höinghaus, K.; Fernandes, R. X.; Curran, H. J., A comprehensive chemical kinetic combustion model for the four butanol isomers. Combust. Flame 2012, 159, 2028-2055.

13. Frassoldati, A.; Grana, R.; Faravelli, T.; Ranzi, E.; Oßwald, P.; Kohse-Höinghaus, K., Detailed kinetic modeling of the combustion of the four butanol isomers in premixed lowpressure flames. Combust. Flame 2012, 159, 2295-2311. 
14. Yasunaga, K.; Mikajiri, T.; Sarathy, S. M.; Koike, T.; Gillespie, F.; Nagy, T.; Simmie, J. M.; Curran, H. J., A shock tube and chemical kinetic modeling study of the pyrolysis and oxidation of butanols. Combust. Flame 2012, 159, 2009-2027.

15. Zhang, J.; Wei, L.; Man, X.; Jiang, X.; Zhang, Y.; Hu, E.; Huang, Z., Experimental and modeling study of n-butanol oxidation at high temperature. Energy Fuels 2012, 26, 33683380.

16. Vasu, S. S.; Sarathy, S. M., On the high-temperature combustion of n-butanol: shock tube data and an improved kinetic model. Energy Fuels 2013, 27, 7072-7080.

17. Cai, J.; Yuan, W.; Ye, L.; Cheng, Z.; Wang, Y.; Zhang, L.; Zhang, F.; Li, Y.; Qi, F., Experimental and kinetic modeling study of 2-butanol pyrolysis and combustion. Combust. Flame 2013, 160, 1939-1957.

18. Hansen, N.; Merchant, S. S.; Harper, M. R.; Green, W. H., The predictive capability of an automatically generated combustion chemistry mechanism: Chemical structures of premixed iso-butanol flames. Combust. Flame 2013, 160, 2343-2351.

19. Sarathy, S. M.; Javed, T.; Karsenty, F.; Heufer, A.; Wang, W.; Park, S.; Elwardany, A.; Farooq, A.; Westbrook, C. K.; Pitz, W. J., A comprehensive combustion chemistry study of 2,5-dimethylhexane. Combust. Flame 2014, 161, 1444-1459.

20. Li, Q.; Hu, E.; Cheng, Y.; Huang, Z., Measurements of laminar flame speeds and flame instability analysis of 2-methyl-1-butanol-air mixtures. Fuel 2013, 263-271. 
21. Togbé, C.; Halter, F.; Foucher, F.; Mounaim-Rousselle, C.; Dagaut, P., Experimental and detailed kinetic modeling study of 1-pentanol oxidation in a JSR and combustion in a bomb. Proc. Combust. Inst. 2011, 33, 367-374.

22. Zhao, L.; Ye, L.; Zhang, F.; Zhang, L. J., Thermal decomposition of 1-pentanol and its isomers: a theoretical study. J. Phys. Chem. A 2012, 116, 9238-9244.

23. Heufer, K. A.; Sarathy, S. M.; Curran, H. J.; Davis, A. C.; Westbrook, C. K.; Pitz, W. J., Detailed kinetic modeling study of n-pentanol oxidation. Energy Fuels 2012, 26, 66786685.

24. Tang, C.; Wei, L.; Man, X.; Zhang, J.; Huang, Z.; Law, C. K., High temperature ignition delay times of $\mathrm{C}_{5}$ primary alcohols. Combust. Flame 2013, 160, 520-529.

25. Li, Q.; Hu, E.; Zhang, X.; Cheng, Y.; Huang, Z., Laminar flame speeds and flame instabilities of pentanol isomer-air mixtures at elevated temperatures and pressures. Energy Fuels 2013, 27, 1141-1150.

26. Dayma, G.; Togbé, C.; Dagaut, P., Experimental and detailed kinetic modeling study of isoamyl alcohol (isopentanol) oxidation in a jet-stirred reactor at elevated pressure. Energy Fuels 2011, 25, 4986-4998.

27. Tsujimura, T.; Pitz, W. J.; Gillespie, F.; Curran, H. J.; Weber, B. W.; Zhang, Y.; Sung, C.J., Development of isopentanol reaction mechanism reproducing autoignition character at high and low temperatures. Energy Fuels 2012, 26, 4871-4886. 
28. Welz, O.; Zádor, J.; Savee, J. D.; Ng, M. Y.; Meloni, G.; Fernandes, R. X.; Sheps, L.; Simmons, B. A.; Lee, T. S.; Osborn, D. L.; Taatjes, C. A., Low-temperature combustion chemistry of biofuels: pathways in the initial low-temperature $(550 \mathrm{~K}-750 \mathrm{~K})$ oxidation chemistry of isopentanol. Phys. Chem. Chem. Phys. 2012, 14, 3112-3127.

29. Sarathy, S. M.; Park, S.; Weber, B. W.; Wang, W.; Veloo, P. S.; Davis, A. C.; Togbé, C.; Westbrook, C. K.; Park, O.; Dayma, G.; Luo, Z.; Oehlschlaeger, M. A.; Egolfopoulos, F. N.; Lu, T.; Pitz, W. J.; Sung, C.-J.; Dagaut, P., A comprehensive experimental and modeling study of iso-pentanol combustion. Combust. Flame 2013, 160, 2712-2728.

30. Lucassen, A.; Warkentin, J.; Hansen, N.; Park, S.; Sarathy, S. M., Detailed analysis of isopentanol combustion chemistry in flames. The 8th US National Combustion Meeting, Park City, Utah, USA, 2013

31. Serinyel, Z.; Togbé, C.; Dayma, G.; Dagaut, P., An experimental and modeling study of 2methyl-1-butanol oxidation in a jet-stirred reacto. Combust. Flame 2014, 161, 3003-3013.

32. Zhang, X.; Yang, B.; Yuan, W.; Cheng, Z.; Zhang, L.; Li, Y.; Qi, F., Pyrolysis of 2methyl-1-butanol at low and atmospheric pressures: Mass spectrometry and modeling studies. Proc. Combust. Inst. 2015, 35, 409-417.

33. Lucassen, A,; Park, S.; Hansen, N.; Sarathy, S. M., Combustion chemistry of alcohols: Experimental and modeled structure of a premixed 2-methylbutanol flame. Proc. Combust. Inst. 2015, 35, 813-820. 
34. Park, S.; Mannaa, O.; Khaled, F.; Bougacha, R.; Mansour, M. S.; Farooq, A.; Chung, S. H.; Sarathy, S. M., A comprehensive experimental modeling study of 2-methylbutanol combustion. Combust. Flame 2015, 162, 2166-2176.

35. Campos-Fernández, J.; Arnal, J. M.; Gómez, J.; Dorado, M. P., A comparison of performance of higher alcohols/diesel fuel blends in a diesel engine. Appl. Energy 2012, 95, 267-275.

36. Gautam, M.; Martin, D. W., Combustion characteristics of higher-alcohol/gasoline blends. Proc. IMechE. Part A: J. Power and Energy 2000, 214, 497-511.

37. Yang, Y.; Dec, J. E., Dronniou N, Simmons B., Characteristics of isopentanol as a fuel for HCCI engines. SAE Int. J. Fuels Lubr. 2010, 3, 725-741.

38. CHEMKIN-PRO 15112. Reaction Design: San Diego, CA, 2011.

39. Metcalfe, W. K.; Burke, S. M.; Ahmed, S. S.; Curran, H. J., A Hierarchical and Comparative Kinetic Modeling Study of $\mathrm{C}_{1}-\mathrm{C}_{2}$ Hydrocarbon and Oxygenated Fuels. Int. J. Chem. Kinet. 2013, 45, 638-675.

40. Mehl, M.; Pitz, W. J.; Westbrook, C. K.; Curran, H. J., Kinetic modeling of gasoline surrogate components and mixtures under engine conditions. Proc. Combust. Inst. 2011, 33, 193-200.

41. Sarathy, S. M.; Kukkadapu, G.; Mehl, M.; Wang, W.; Javed, T.; Park, S.; Oehlschlaeger, M. A.; Farooq, A.; Pitz, W. J.; Sung, C.-J., Ignition of alkane-rich FACE gasoline fuels and their surrogates. Proc. Combust. Inst. 2015, 35, 249-257. 
42. Fieweger, K.; Blumenthal, R.; Adomeit, G., Self-ignition of S.I. engine model fuels: a shock tube investigation at high pressure. Combust. Flame 1997, 109, 599-619.

43. da Silva, G.; Bozzelli, J. W.; Liang, L.; Farrell, J. T., Ethanol oxidation: Kinetics of the $\alpha-$ hydroxyethyl radical $+\mathrm{O}_{2}$. J. Phys. Chem. A 2009, 113, 8923-8933.

44. Tsujimura, T.; Pitz, W. J.; Yang, Y.; Dec, J. E., Detailed kinetic modeling of HCCI combustion with isopentanol. SAE Int. J. Fuels Lubr. 2011, 4, 257-270.

45. Vuilleumier, D.; Kozarac, D.; Mehl, M.; Saxena, S.; Pitz, W. J.; Dibble, R. W.; Chen, J.Y.; Sarathy, S. M., Intermediate temperature heat release in an HCCI engine fueled by ethanol/n-heptane mixtures: an experimental and modeling study. Combust. Flame 2014, $161,680-695$.

46. Sjöberg, M.; Dec, J. E., Comparing late-cycle autoignition stability for single- and twostage ignition fuels in HCCI engines. Proc. Combust. Inst. 2007, 31, 2895-2902.

47. Liu, W.; Sivaramakrishnan, R.; Davis, M. J.; Som, S.; Longman, D. E.; Lu, T., Development of a reduced biodiesel surrogate model for compression ignition engine modeling. Proc. Combust. Inst. 2013, 34, 401-409.

48. Sarathy, S. M.; Niemann, U.; Yeung, C.; Gehmlich, R.; Westbrook, C. K.; Plomer, M.; Luo, Z.; Mehl, M.; Pitz, W. J.; Seshadri, K.; Thomson, M. J.; Lu, T., A counterflow diffusion flame study of branched octane isomers. Proc. Combust. Inst. 2013, 34, 10151023. 
49. Lu, T.; Law, C. K., A direct relation graph method for mechanism reduction. Proc. Combust. Inst. 2005, 30, 1333-1341.

50. Lu, T; Law, C. K., Linear time reduction of large kinetic mechanisms with directed relation graph: n-Heptane and iso-octane. Combust. Flame, 2006, 144, 24-36.

51. Dec, J. E.; Yang, Y., Boosted HCCI for high power without engine knock and with ultralow NOx emissions - using conventional gasoline. SAE Int. J. Engines 2010, 3, 750-767.

52. Sjöberg, M.; Dec, J. E., Comparing late-cycle autoignition characteristics and HCCI performance for wide ranges of engine speed, load and boost. SAE Int. J. Engines 2010, 3, 84-106. 